San Jose State University

SJSU ScholarWorks

Master's Theses

Master's Theses and Graduate Research

2005

\title{
Effects of management on lepidoptera and parasitoids in tropical banana agroecosystems
}

Darya Chehrezad

San Jose State University

Follow this and additional works at: https://scholarworks.sjsu.edu/etd_theses

\section{Recommended Citation}

Chehrezad, Darya, "Effects of management on lepidoptera and parasitoids in tropical banana agroecosystems" (2005). Master's Theses. 2702.

DOI: https://doi.org/10.31979/etd.3mjh-sz8x

https://scholarworks.sjsu.edu/etd_theses/2702

This Thesis is brought to you for free and open access by the Master's Theses and Graduate Research at SJSU ScholarWorks. It has been accepted for inclusion in Master's Theses by an authorized administrator of SJSU ScholarWorks. For more information, please contact scholarworks@sjsu.edu. 


\title{
EFFECTS OF MANAGEMENT ON LEPIDOPTERA AND PARASTTOIDS IN
} TROPICAL BANANA AGROECOSYSTEMS

\author{
A Thesis \\ Presented to \\ The Faculty of the Department of Environmental Studies
}

San Jose State University

In Partial Fulfillment

of the Requirements for the Degree

Master of Science

by

Darya Chehrezad

May 2005 
UMI Number: 1427157

Copyright 2005 by

Chehrezad, Darya

All rights reserved.

\section{INFORMATION TO USERS}

The quality of this reproduction is dependent upon the quality of the copy submitted. Broken or indistinct print, colored or poor quality illustrations and photographs, print bleed-through, substandard margins, and improper alignment can adversely affect reproduction.

In the unlikely event that the author did not send a complete manuscript and there are missing pages, these will be noted. Also, if unauthorized copyright material had to be removed, a note will indicate the deletion.

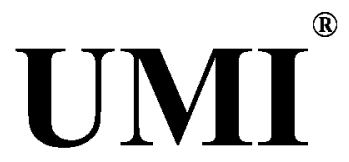

UMI Microform 1427157

Copyright 2005 by ProQuest Information and Learning Company. All rights reserved. This microform edition is protected against unauthorized copying under Title 17, United States Code.

ProQuest Information and Learning Company 300 North Zeeb Road

P.O. Box 1346

Ann Arbor, Ml 48106-1346 
(c) 2005

Darya Chehrezad

ALL RIGHTS RESERVED 
APPROVED FOR THE DEPARTMENT OF ENVIRONMENTAL STUDIES

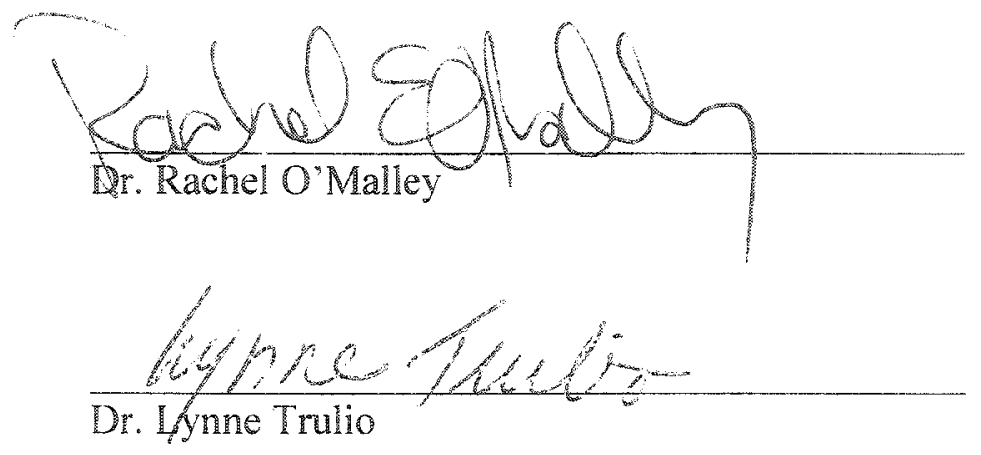
Mher B. Matrots Z

Dr. Robert B. Matlock, Jr., Senior Research Fellow, Department of Ecology and Evolutionary Biology. Tulane University

\section{APPROVED FOR THE UNIVERSITY}

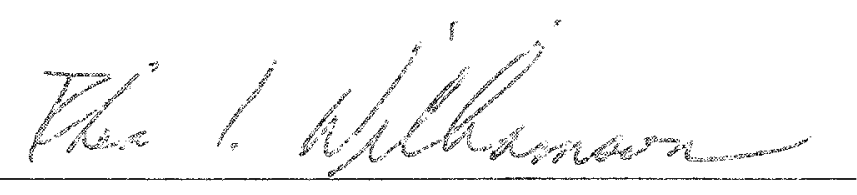




\title{
ABSTRACT \\ ERTECTS OF MANAGEMENT ON LEPIDOPTERA AND PARASITOMDS IN TROPICAL BANANA AGRORCOSVSTEMS
}

\author{
by Darya Chehrezad
}

Biological control of lepidopteran pests on banana plantations by parasitoids has never been adequately researched. Understanding the population dynamics of lepidopteran defoliators and their naturally occurring parasitoids in the Atlantic zone of Costa Rica is essential for a more complete understanding of the relationship between pesticide, pest, and parasitoid function in this wet tropical banana agroecosystem. This research encompassed three goals: (1) to better understand the current abundance and diversity of lepidopteran pests on banana plantations, (2) to gauge parasitism and its relationship to chemical inputs, and (3) to gauge possible beneficial effects of incorporating a nectar-producing source into banana plantations. The results of this research provide insight into many pest-predator functions in wet tropical agroecosystems, notably: (1) many common lepidopteran pests of banana are rare in analogous systems, (2) some lepidopteran populations are lower in high-input plantations, and (3) tachinid parasitism is higher in high-input plantations, while, conversely, hymenopteran abundance is lower in high-input plantations. No effects of intercropping were detected. The conclusions and recommendations in this study add to the current understanding of the role of insect ecology in tropical agriculture and provide a baseline for studying pest-parasitoid interactions in tropical banana agroecosystems. 


\section{ACKNOWLEDGMRNTS}

I am pleased to thank the many people who have helped me in the various phases of this work. I thank R. O'Malley, R. Matlock, L. Dyer, and D. Cubillo for their valuable ideas and input; H. Garcia, A. Chehrezad, and other assistants for their invaluable assistance in the field and laboratory; and D. Carpenter and $\mathrm{A}$. Johnson for their review and improvements to this manuscript. This research was funded by research grants from Syngenta, San Jose State University, and USDA. 


\section{TABLE OF CONTENTS}

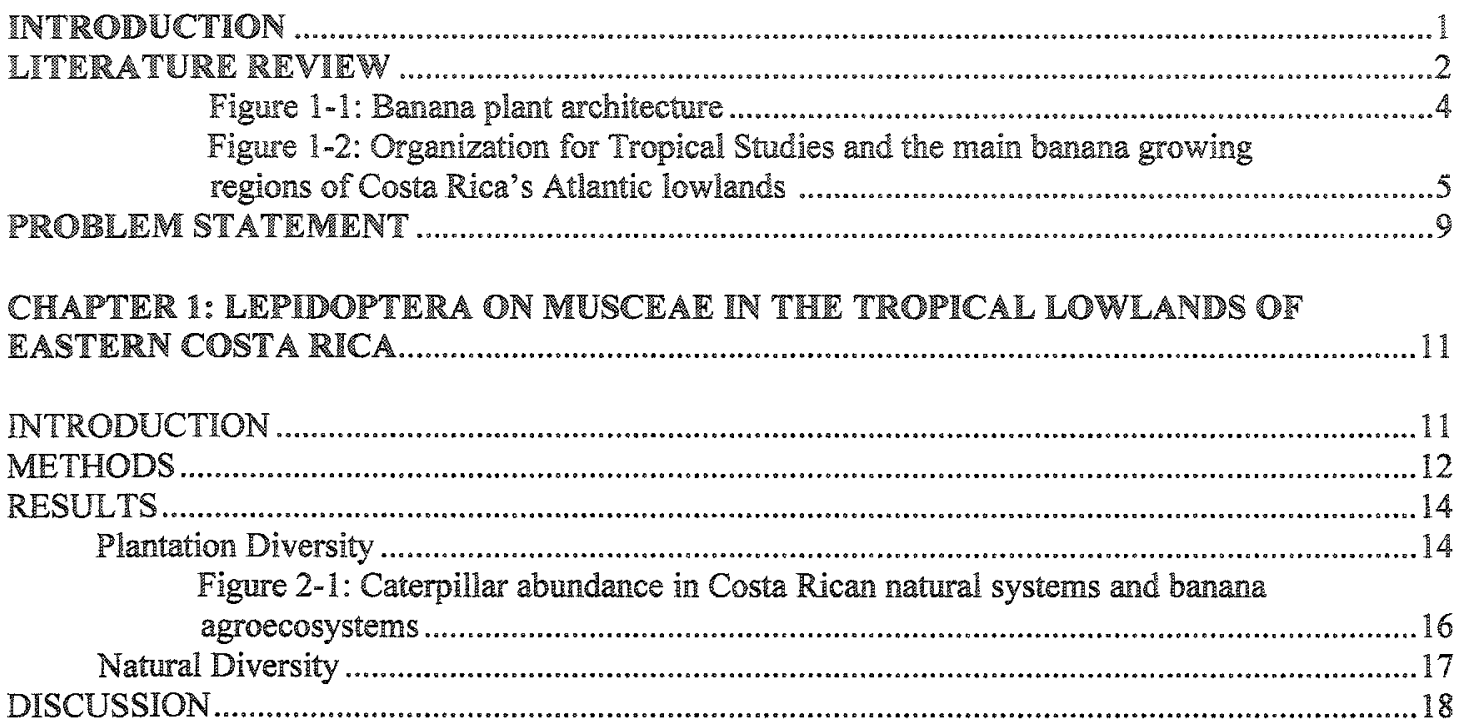

CHAPTER 2: EFFECTS OF INPUT LEVEL AND SEASONALITV ON PARASITISM AND

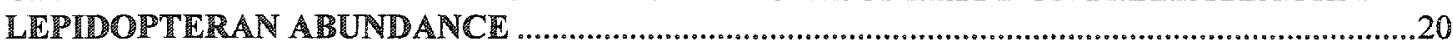

INTRODUCTION

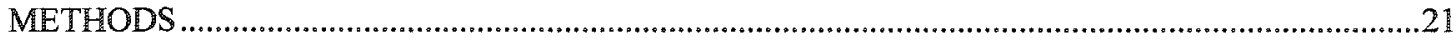

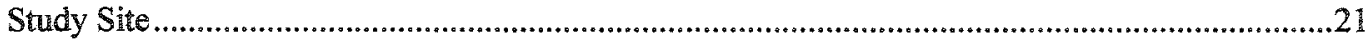

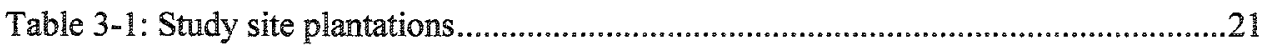

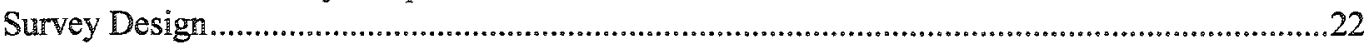

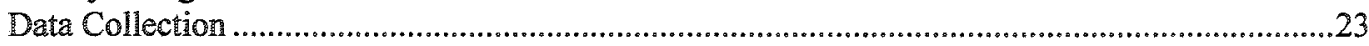

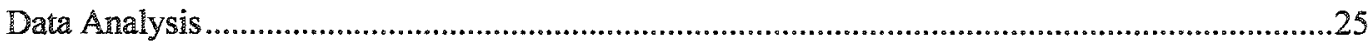

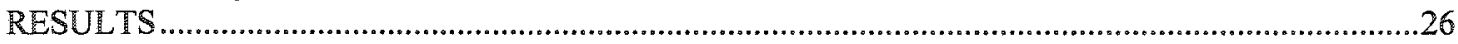

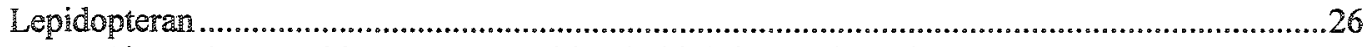

Figure 3-1: Lepidoptera composition in high-input plantations.........................................26

Figure 3-2: Lepidoptera composition in low-input plantations ........................................227

Table 3-2: ANOVA repeated-measures results of effect of season (wet and dry) on

lepidopteran abundance..........................................................................................................2. 27

Figure 3-3: Mean lepidopteran abundance in high and low-input plantations .................28

Figure 3-4: Mean $A$. viridis abundance in high and low-input plantations .......................28

Figure 3-5: Mean C. memnon abundance in high and low-input plantations....................22

Parasitism...............................................................................................................................29

Figure 3-6: Parasitoid diversity on $A$. viridis in high-input plantations ...........................30

Figure 3-7: Parasitoid diversity on A. viridis in low-input plantations .............................30

Figure 3-8: Parasitoid diversity on C. memnon in high-input plantations........................32

Figure 3-9: Parasitoid diveristy on C. memnon in low-input plantations ...........................32

Figure 3-10: Parasitoid diversity on $O$. tamarindi in high-input plantations ....................33

Figure 3-11: Parasitoid diversity on 0 . tamarind in low-input plantations ......................33

Table 3-3: ANOVA repeated-measures results of effect of pesticide level (high-input

and low-input) on percent parasitism ...................................................................................34

Figure 3-12: Parasitoid abundance in high and low-input plantations ...............................34

Figure 3-13: Dipteran abundance in high and low-input plantations ................................35

Figure 3-14: Total percent parasitism on C. memnon in high and low-input plantations .36 


\section{TABLE OF CONTENTS}

Table 3-4: ANOVA repeated-measures resuts of effect of season (wet and dry on percent parasitism ........................................................................................................36 Table 3-5: Pearson's correlation coefficient analysis of parasitoid abundance ..................37

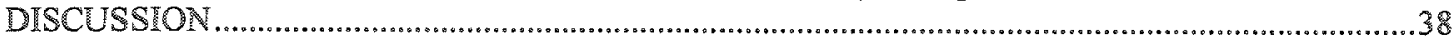

CHAPTER 3: THE EFTECT OF INTERCROPPING ON LEPIDOPTERAN AND

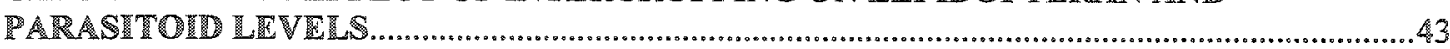

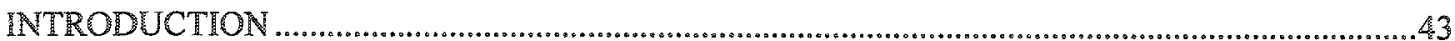

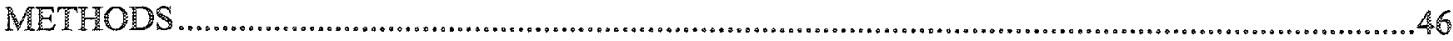

Study Design.................................................................................................................................46

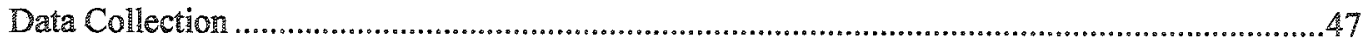

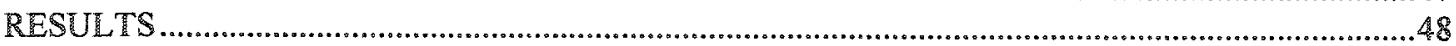

Table 4. 1: Parasitism on lepidopteran in intercropped and control areas ..........................49

Table 4-2: Paired t-test results of effect of intercropping on lepidopteran abundance........49

Table 4-3: Paired t-test results of effect of intercropping on percent parasitism ...............50

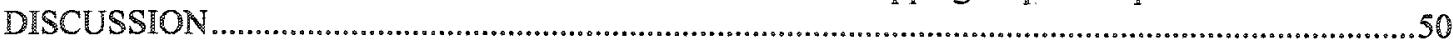

CHAPTER 4: OVERALL CONCLUSIONS AND RECOMMENDATIONS..............................52

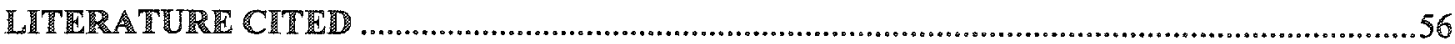




\section{INTRODUCTION}

High rainfall, low soil nutrient content, a nearly constant growing season, and an extremely diverse pest community combine to seriously augment the use of high-input agricultural systems in the wet tropics (Vandermeer 2001). Large-scale tropical agriculture has become notorious for its use of pesticides and fertilizers to combat aggressive pest problems, yet scientific understanding of wet tropical agroecology remains in its infancy. As a result, using insecticides in wet tropical systems has disrupted beneficial insect populations to the point of causing secondary outbreaks of otherwise benign pests (Ostmark 1974 and Stephens 1984).

In tropical banana agroecosystems, heavy pesticide use is common. In Costa Rica approximately $33 \%$ of imported pesticides are used in the production of exported bananas (Thrupp 1990). Current banana pesticide regimes typically include nematicides, fungicides, and herbicides, plus the occasional use of insecticides; additionally, all plantations cover developing fruit with plastic bags impregnated with chlorypyrifos.

Costa Rica is a large consumer in the 25-billion dollar global market for pesticides. Of this global market, Latin America constitutes 9.5\%. Wesseling et al. (1993) point out that within Central America, Costa Rica is the top pesticide consumer, using nearly double that of any other Central American country and eight times more pesticide per hectare than the rest of the world. The authors report that pesticide use on Costa Rican bananas amounts to more than $44 \mathrm{~kg}$ applied per hectare each year. Costa Rica's agrarian-based economy, combined with its relatively high level of capitalization 
and debt, causes Costa Rica to use an exceptionally high volume of pesticides to sustain a high level of export-quality fruit.

\section{LITERATURE REVIEW}

The banana (family: Musaceae, genus: Musa) is a large herbaceous plant that grows from a corm, has a pseudostem composed of tightly packed leaves, and reproduces by sending out suckers (Figure 1-1). Bananas require high heat, high humidity, high light intensity, a large amount of water, and good drainage (Champion 1963, Hansen 1988 , and Jones 2000). Fruit is ready for harvest, depending on variety and environmental conditions, anywhere from nine to 16 months after planting and approximately 85 to 110 days after flowering (Jones 2000).

Bananas are an important food and economic crop in more than 120 countries, primarily in the tropics and subtropics (Champion 1963, Jones 2000, and Hansen 1988). About $90 \%$ of the world's 88 million-ton banana production is consumed by the domestic market and produced in small plantations and gardens. The remaining $10 \%$ of production is for export markets (Jones 2000). Most bananas that are grown for export to the United States are cultivated in Latin America and the Caribbean, where they play an important economic role for those countries. Typically, bananas for export are cultivated as a monocrop, and, because of their growth requirements, have historically been cultivated in tropical lowiands.

The Costa Rican export market primarily supplies Europe and the United States, where bananas are the number one fruit consumed per capita. Two banana varieties 
constitute the majority of those grown for export in Costa Rica, Valery and Grand Nain (Cubillo pers com 2001). In Costa Rica, most export banana production occurs in the Guacimo, Limon, Matina, Pococi, Sarapiqui, Siquirres, and Talamanca regions of the Atlantic lowlands (Figure 1-2). 
Tigure $1-1$

Bamana plant arehitecture (Champion 1963).

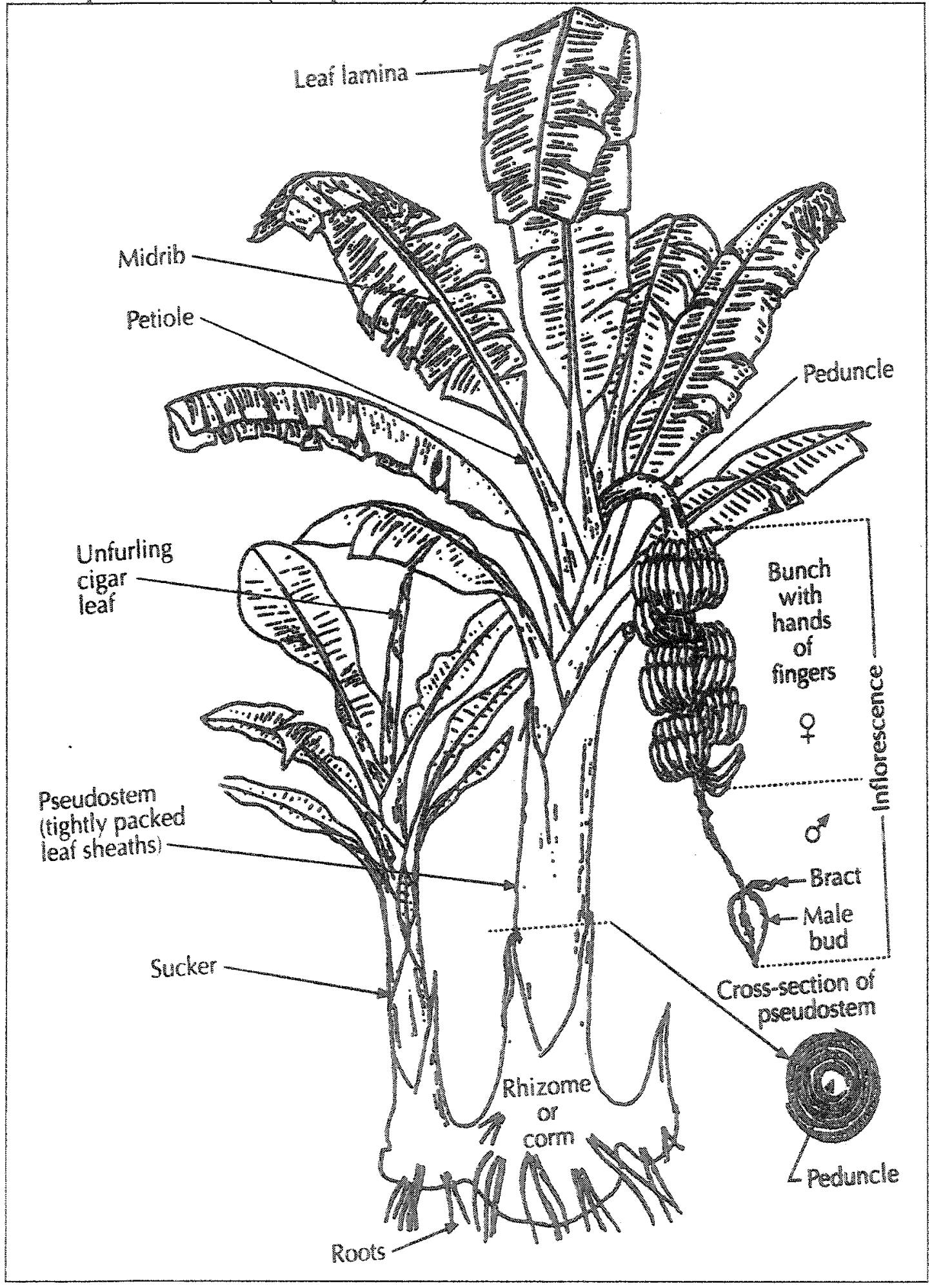


Figure 1-2

Organization for Tropical Studies and the main bsmana growimg regions of Costa Rica's Atimatic lowlands (University of Texas 2003).

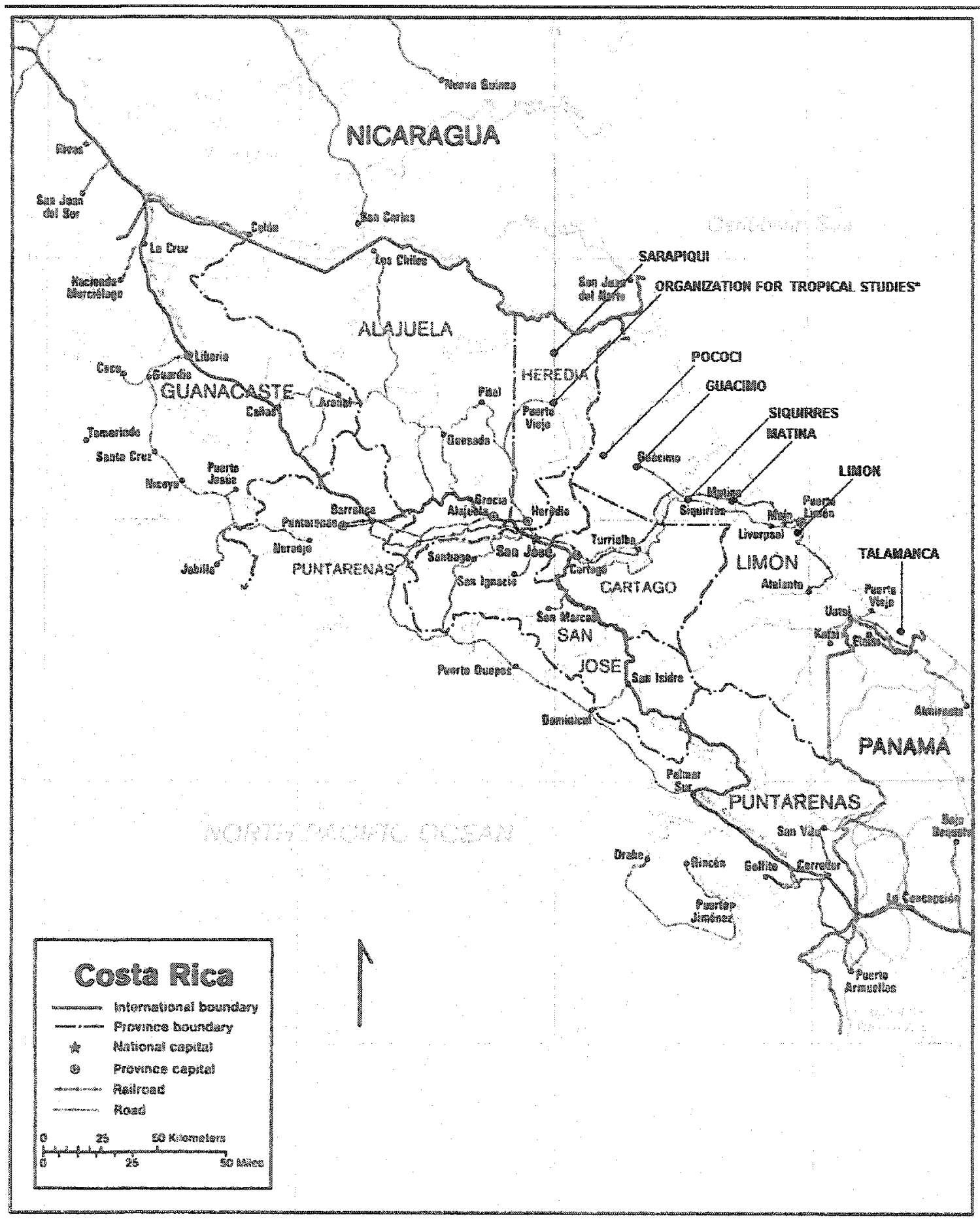

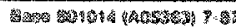


Until the introduction of broad-spectrum insecticides the complex beneficial insect community appears to have kept populations of insect pests low on Costa Rican banana plantations (Thrupp 1990). Prior to the 1950 's, only two insect species were considered significant pests in banana production: the banana corm weevil (Cosmopolites sordiadus) and the native thrip (Chaetaneophothrips orchidii) (Stephens 1984). In the mid-1950's, an attempt to control these pests in the Pacific region of Costa Rica led to applications of dieldren (an organochlorine insecticide). The results of the applications were disastrous. Although the chemical initially controlled the pests, in a matter of months secondary pest outbreaks occurred.

The first insect outbreak resulting from the use of insecticides was the banana stalk borer (Lepidoptera: Castnimera humbolt), which quickly caused economic losses through decreased production. The use of broad-spectrum insecticides and resulting agroecological disruption lasted nearly 20 years and cost the banana industry millions of dollars (Stephens 1984 and Thrupp 1990).

Unable to keep up with the growing tide of outbreaks, the banana industry employed a team of entomologists to examine the surge of outbreaks. This group of researchers concluded that the insecticides were severely disrupting the natural communities of beneficial insects that occurred in Costa Rica (Lara 1970, Ostmark 1974, and Stephens 1984). Soon after this conclusion, the banana industry in Costa Rica decided to eliminate the widespread use of aerially applied broad-spectrum insecticides. By 1973 , most aerial applications of insecticides were stopped, and within two years the banana agroecosystems re-stabilized (Stephens 1984 and Thrupp 1990). 
This pattem of insect outbreaks does indicate the presence of an effective biocontrol mechanism in Costa Rica. Hansen (1988) argues that the biological control mechanism probably consists of a large suite of parasitoids. This conclusion is also supported by the observation that banana plantations that have rarely, or never, been treated with organochlorine insecticides did not experience outbreaks as extreme as those under conventional insecticide applications (Ostmark 1974).

Most parasitoids are either Dipteran or Hymenopteran. Godfray (1994) estimates that parasitoids constitute $20 \%$ to $25 \%$ of all insects, an estimated 800,000 species worldwide. The life cycles of parasitoids vary greatly, but generally consist of an egg, larval, pupal, and adult stage. The main requirements for a successful parasitoid life cycle are: 1) accessible nectar source, 2) successful location of a host, 3) oviposition, and 4) larval and pupal development (Godfray 1994 and Powell 1986). Host Lepidoptera are parasitized in egg, larva, pupa, or adult stages depending on the parasitoid species (Powell 1986).

Matlock and de la Cruz (2002) conducted a study of parasitic hymenoptera in banana plantations in the Golfito region of Costa Rica and found a negative correlation between the levels of insecticides used and the diversity and abundance of hymenoptera trapped on banana plantations. Matlock and de la Cruz did not investigate percent parasitism of herbivores, which is essential for assessing the impact of parasitoids on pests in varying plantation conditions.

Memmott et al. (1993) studied the mortality of leaf miners caused by predation and parasitism in Costa Rica. An interesting conclusion of Memmott et al.'s study is that 
predation of herbivores by ants was found to be significant in agricultural ecosystems. Price et al. (1980) also examined herbivore-natural enemy interactions and found that host-enemy interactions are influenced by habitat stability, and that those agroecosystems with high ecological stability, such as banana, facilitate long-term biological control of pests.

Caterpillar density often varies among sites and microhabitats. Sparrow et al. (1994) found that different transects vary in abundance and richness of Lepidoptera within a study area, including forest edges, forest light gaps, forest interior, and varying elevations. Manley (1985) concluded that $90 \%$ of the lepidopteran pest Antichloris viridis is found on the oldest $50 \%$ of the banana leaves, and $60 \%$ of the total herbivory can be found on the oldest $25 \%$ of banana leaves. Similarly, Harrison (1963b) found that herbivore larvae are unevenly distributed on banana plants. Harrison (1963b) states that most larvae of Arachis albescens, Caligo memnon, and Antichloris viridis are found between the third and the last leaf (counting the bottom extended leaf as the last) (Figure 1-1). This relationship between leaf age and herbivory, which is attributed to the physiological state of banana, is of practical importance for this research, which relies on locating and collecting active herbivores.

Arthropod biodiversity has been shown to be significantly higher in more diverse and less chemically intensive agroecosystems in Central America and Mexico (Matlock and Cruz 2002 and 2003, Perfecto and Snelling 1995, and Soto-Pinto et al. 2000). Vandermeer et al. (1998) argues that understanding insect biodiversity is key to successfully evaluating the mechanisms that will increase beneficial biodiversity in 
agroecosystems. This research investigated the biodiversity of both herbivores and parasitoids.

\section{PROBLEM STATEMENT}

The goal of this research was to describe the variability and diversity of Lepidoptera and parasitoid communities in banana agroecosystems in Costa Rica, examine the effectiveness of parasitoids across different plantation types, and assess the causes of that variability. By conducting a survey of parasitoid control of lepidopteran pests, the largely circumstantial evidence (Thrupp 1990) that lepidopteran defoliators are regulated by parasitoids in banana was examined. Additionally, an experiment that examined the potential beneficial effect of nectar-producing vegetation and its relationships with parasitoid and pest diversity and abundance was conducted.

This study contributes to a more comprehensive understanding of naturally occurring and enhanced biological pest control, potentially facilitating a reduction in the use of pesticides in Costa Rica. In this study, the following hypotheses was tested:

(1) The lepidopteran diversity in banana agroecosystems is a subset of the documented diversity in natural systems.

(2) Low-input banana plantations will have a significantly

(a) higher abundance of parasitoids,

(b) higher diversity of parasitoids,

(c) higher percentage of parasitism, and

(d) lower abundance of lepidopteran herbivores 
than do higher-input banana plantations.

(3) Both lepidopteran and parasitoid populations oscillate between wet to dry seasons.

(4) Intercropping with a nectar source, $F$. macrophylla, can increase beneficial parasitism in banana plantations, and will
(a) increase the abundance of parasitoids,
(b) increase the diversity of parasitoids,
(c) increase the percentage of parasitism, and
(d) reduce the abundance of caterpillars. 


\section{CHAPTER 1: LEPIDOPTERA ON MUSACEAR IN THE TROPICAL LOWLANDS OF EASTERN COSTA RICA}

\section{INTRODUCTION}

Banana plantations have been described as mimics of tropical forest systems, and repositories of natural diversity. Yet no attempts have been made to quantify the extent to which they support natural arthropod diversity, as opposed to hosting a normal assemblage of invertebrates specializing on banana. In an attempt to contrast diversity of natural systems with banana agroecosystems, the lepidopteran diversity in banana was surveyed and contrasted with the diversity of lepidopteran reported in Musaceae in natural surrounding forest ecosytstems.

DeVries (1987) published an extensive survey of the natural history of the lepidopteran species occurring on Musaceae, particularly the Nymphalidae. Two additional host-specific surveys, and therefore useful lepidopteran surveys, are the Janzen-Hallwachs database (Janzen and Hallwachss 2003) and the Dyer database (Dyer 2003).

The Dyer database provides approximately 10 years of lepidopteran information from collections at the La Selva biological station in the wet neotropical forest, located in the Atlantic zone of Costa Rica. The benefit of this database is the close proximity of the collecting area to many of the plantations surveyed for this experiment. The drawback is that there are far fewer (less than 10) recorded herbivores on Musaceae because of the extremely low numbers of naturalized banana plants at La Selva. 
Ironically, an equally complete database of lepidopterans on banana plantations does not currently exist. The purpose of this survey was thus to document the current abundance and diversity of lepidopteran herbivores occurring in Costa Rican banana plantations. This survey data from Musaceae in plantations was contrasted with the current data describing lepidopteran diversity on Musaceae in Costa Rican natural systems, to asses how closely banana plantations mimic natural forest diversity.

\section{METHODS}

To assess seasonal variation in parasitoid communities, repeated surveys were conducted on six plantations for three months during the 2001 "wet" season (July, August, and September), and three months during the 2002 "dry" season (January, February, and March).

At the beginning of the study, transects were randomly selected for each plantation. Each transect was at least 50 meters from the plantation edge to minimize the edge effect, which has been shown to yield a higher percent of parasitism (Broadmann et al. 1997). Two people conducted sampling for three hours from approximately 7:00 A.M. to $10: 00$ A.M. Cooler morning hours were chosen because midday heat causes many lepidopterans to descend from canopy foliage to escape the higher temperatures (Dyer pers com 2001; Cubillo pers com 2001).

Transects were 20 meters wide and ran the complete length of the plantation, and adjacent transects were separated by 50 meters. To maximize the number of Lepidoptera collected, sampling was initially conducted along a transect for 15 minutes. If no 
Lepidoptera were found during the initial 15 -minute search, researchers would move 50 meters down the transect to search for another 15 minutes. If lepidopterans were found, sampling continued in the area until 15 minutes had elapsed after the last larva was collected, at which point the researchers moved down the transect 50 meters, repeating this method throughout the three hours. This method was used to maximize the number of lepidopterans collected. If a transect was completed before the three-hour sampling period terminated, sampling was continued along another predetermined random transect. Like previous research on banana, this research utilized the preexisting cable system (used for transportation of fruit to the packing plant) to assess distance along transects. All plantations in this study had cable systems with support structures every 10 meters, allowing researchers to follow exact distances along each transect.

Banana plants average 10-15 leaves at any time (Jones 2000). Because previous research (Manley 1985 and Harrison 1963b) found that caterpillars are most often found on the lower (older) leaves, this research confined caterpillar search to the bottom eight leaves (Manley 1985 and Harrison 1963b). The lowest extended leaf was counted as leaf number one, and examination for Lepidoptera continued up to leaf number eight. If a plant had fewer than eight leaves all leaves were inspected. Censuses involved a complete inspection of every plant within each $50 \times 20$-meter swath sample area.

To document Lepidoptera diversity on plantations, all lepidopteran species found were collected and recorded. All larvae collected were placed in collection bags and marked with the date and plantation name before being brought back to the laboratory for 
taxonomic identification and rearing. Only larvae were included in the lepidopteran survey; eggs, pupae, and adult lepidopteran data were not recorded.

Many of the Lepidoptera species collected are well known and required no further taxonomic identification. For the species that were not easily identifiable using lepidopteran keys, I utilized the expertise of entomologists at Tulane University, the Arthropods at La Selva Project (ALAS), Corporacion Bananera Nacional (CORBANA), and the mentioned on-line Dyer and Janzen-Hallwachs databases. $\mathbb{H}$. Garcia, who has worked as a field assistant collecting, rearing, and identifying the myriad Lepidoptera from throughout the Eastern Lowlands of Costa Rica, was an invaluable resource in identifying wet tropical Lepidoptera.

\section{RESULTS}

\section{Plantation Diversity}

A total of 2,722 Lepidoptera were collected during this survey, representing seven families and 15 species: Limocodidae (four species), Hesperiidae (three species), Arctiidae (two species), Nymphalidae (two species), Noctuidae (two species), Megalopygidae (one species), and Saturniidae (one species) (Figure 2-1). A. viridis constituted $50.88 \%(1,385)$ of the Lepidoptera collected in this survey. The other Arctiid species encountered in the survey was Hypercompe laeta, which accounted for only $0.18 \%$ of the total Lepidoptera collected.

The second most abundant family of Lepidoptera collected was Nymphalidae. Two species of Nymphalidae were collected for a total of 1,066 Lepidoptera, which was 
$39.16 \%$ of the total Lepidoptera collected in the survey. The most abundant

Nymphalidae was C. memnon, with 942 individuals collected (34.61\% of the total Lepidoptera collected in the survey). The second most abundant Nymphalidae collected was $O$. tamarindi with 124 ( $4.56 \%$ of the total Lepidoptera collected).

Following A. viridis (Arctiidae), C. memnon, and O. tamarindi (Nymphalidae) was Acharia horrida (Limacodidae), the fourth most abundant lepidopteran species collected in banana plantations during this study. A total of $144 \mathrm{~A}$. horrida were collected (5.29\% of all Lepidoptera), followed by Acharia apicalis with 45 individuals collected (1.65\% of all Lepidoptera).

The three species of Hesperiidae collected totaled 47 (1.73\% of Lepidoptera). Phanus sp. (not identifiable to species) was the most abundant species of Hesperiidae at $40(1.47 \%)$, followed by Talides sergestus at four $(0.15 \%)$, and Thracides phidon at three $(0.11 \%)$. Two undescribed species of Noctuidae were collected during the survey. Two specimens of one other undescribed species of Noctuidae were collected $(0.07 \%)$. Only one species of the Saturniidae family, Automeris tridens, was collected during the study. The two Automeris tridens collected were only $0.07 \%$ of the total Lepidoptera collected. Similar to the Saturniidae family, only one species of Megalopygidae was found on Musaceae during this study. One Megalopyge albicollis was collected, $0.04 \%$ of the total Lepidoptera, during the study. Hesperiidae, Saturniidae, and Megalopygidae are not considered to be economically important pests of banana in Costa Rica (Cubillo pers com 2001) (Figure 2-1). 
Figigre 2-1

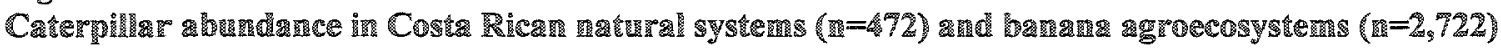
(Janzen and Hallwachs 2003).

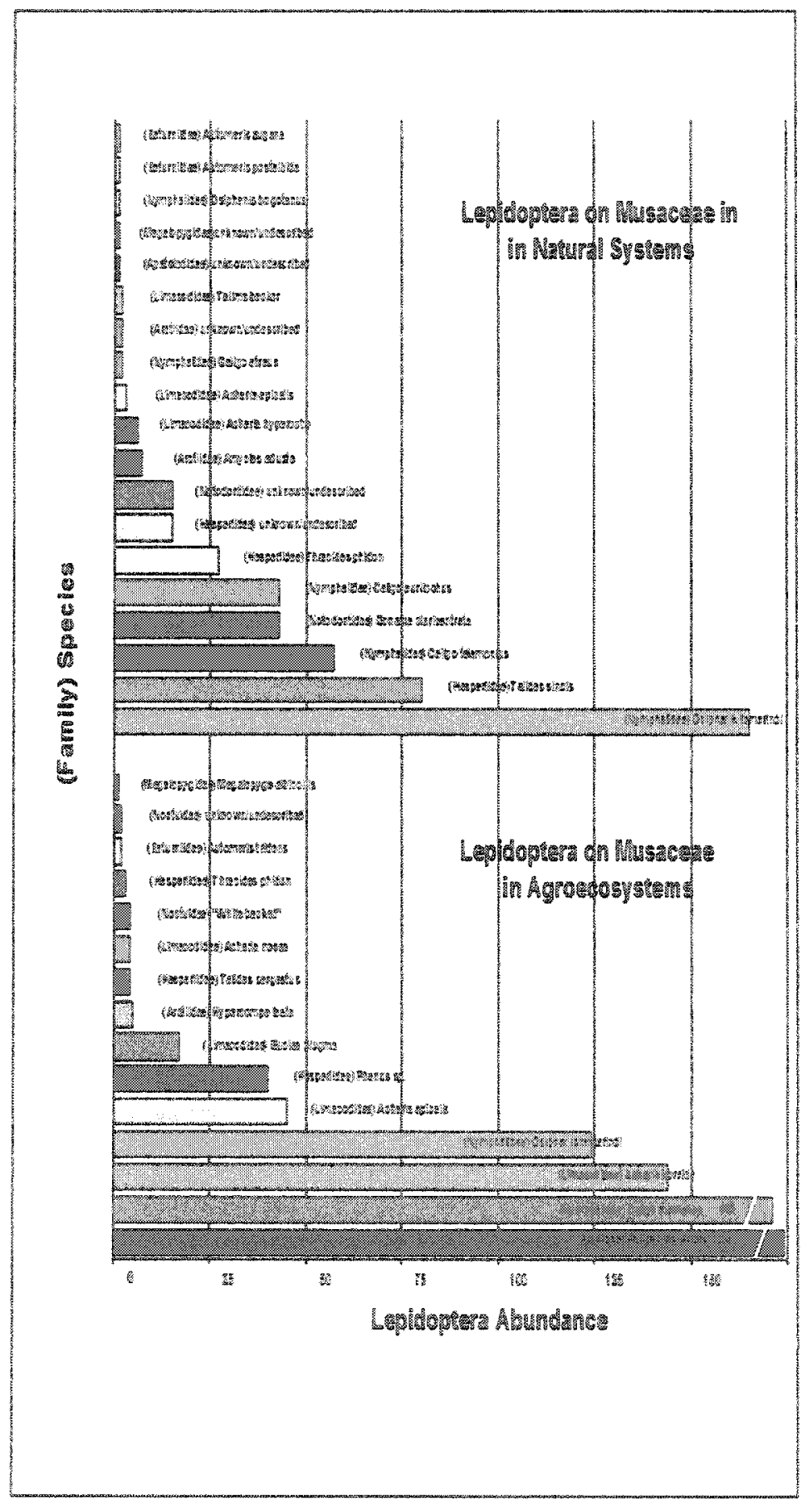




\section{Natural Diversity}

The Dyer database lists eight species of lepidopterans occurring on the closely related Heliconiaceae: Astroptes sp. and Thracides sp. (Hesperiidae), Achoria ophelians (Limacodidae), Caligo eurilochus, Caligo illoneus Oberon, and Caerois gerdrudtus (Nymphalidae).

The Janzen-Hallwachs database catalogues all Lepidoptera collected from 19862001 in the natural systems in the Guanacaste region of Costa Rica. Though it contains data on a dry Pacific forest rather than a wet tropical Atlantic one, the database still provides information for the cross referencing of lepidopteran species with their host plants (in this case, Musaceae). Over the 16-year period of their study, Janzen and Hallwachs sampled numerous $(\mathrm{n}=472)$ lepidopterans on Musaceae in the Guanacaste area. The database, which lists abundance as well as diversity, provides data that are comparable to this lepidopteran diversity survey (Figure 2-1).

Janzen and Hallwachs found 19 species and nine families of Lepidoptera on naturalized Musaceae and Heliconiaceae in the Guanacaste region of Costa Rica. Of the 472 lepidopteras Janzen and Hallwachs recorded, $35 \%$ were O. tomarindi (Nymphalidae), 17\% were Talides sinois (Hesperidae), 12\% were Caligo telamonius (Nymphalidae), 9\% were Donoma claricentrata (Notodontidae), and 9\% were Caligo eurilochus (Nymphalidae) (Figure 2-1). 


\section{DISCUSSION}

Only two species were found in both natural forest and agroecosystem on Musaceae Acharia apicalis and Osiphanes tamarindi. A. viridis constituted more than hal of the total lepidopterans collected on banana in this study, and over a third were $C$. memnon. These pests have been associated with banana faming since its inception in Costa Rica (Ostmark 1974). These defoliators, which at times have decimated plantations, have been recorded in the literature as attacking banana as well, and appear in numerous current articles researching pests of banana (Lara 1970 and Stephens 1984). In stark contrast, little reference exists of these Lepidoptera occurring in Costa Rican natural systems (Janzen and Hallwachss 2003 and Dyer 2003).

A. viridis and C. memnon seem to be unusual specialists found largely in agroecosystems. Figure 2-1 shows the discrepancy between abundance of $A$. viridis and C. memnon in natural systems versus the extremely high abundance of this herbivore in agroecosystems. Both $A$. viridis and $C$. memnon are reported as pests of banana in Guanacaste as well (Janzen and Hallwachss 2003), indicating that the obscured discrepancy is not simply biogeographical.

Unlike $A$. viridis and $C$. memnon, a relatively large percentage $(7.09 \%)$ of lepidopteran on naturalized Musaceae are in the family Limacodidae. Commonly referred to as the slug caterpillar, Limacodidae are found on Musaceae, although they have not been reported as a significant pest on banana. Nor have Limacodidae been associated with any previous lepidopteran outbreaks in banana. Because these species of Limacodidae are urticating, they occasionally interfere with workers' ability to harvest in 
the field, but they do not reach economically significant levels (Cubillo pers com 2001). Reflecting a different abundance pattern, $O$. tamarindi's abundance in agricultural systems was very similar to its abundance in natural systems (Figure 2-1).

Talides sinois (Hesperiidae) constituted 12\% of the Lepidoptera found on Musaceae by Janzen and Hallwachs. However, this species of Hesperiidae, which is somewhat abundant in natural systems, was not recorded as occurring at all in banana plantations. Another Hesperiidae, T. sinois, was. A possible reason for the relatively high abundance in Guanacaste is that this particular species of Hesperiidae prefers the more arid region of Guanacaste.

Chapman (1939) described factors contributing to insect outbreaks as a combination of the relaxation of a biotic control mechanism and/or the result of a biological migration. Because the primary lepidopteran pests of banana are native to the Americas, biological migration may be the cause of many the new species this survey found in banana plantations. Others, such as noctuids in agroecosystems, may have been introduced or switched hosts to take advantage of the abundance of Musaceae. In conclusion, although little overlap was recorded at the species level between agroecosystems and natural systems, the diversity of lepidopterans in banana agroecosystems compared favorably with natural system diversity. 


\section{CHAPTER 2: EFIECTS OF INPUT LEVEL AND SEASONALITY ON PARASITISM AND LEPIDOPTERAN ABUNDANCE}

\section{INTRODUCTION}

To understand the function of the naturally occurring suite of lepidopteran pestcontrolling parasitoids, it is necessary to research the biological history as well as conduct field research in agricultural systems. The motivation for this research lies in the historical record that indicates a strong suite of biological control organisms in banana plantations.

Thrupp (1990) outlines the social and ecological damage that plagued the bananagrowing regions of Costa Rica beginning in the 1950's. In a similar article, Stephens (1984) examined the banana industry's high level of pesticide use and the resulting ecological damage. Both Thrupp and Stephens identify the disruption of the insect herbivore - natural enemy interactions, caused by initial insecticide applications, as the main reason for subsequent insecticide overuse. Ostmark (1974) supports the conclusion that the secondary effect of insecticide use on banana plantations likely caused a sharp rise in lepidopteran pest levels. This secondary effect of insecticide use in the 1950's is thought to be due to a suppression of the naturally occurring beneficial hymenopteran fauna populations (Ostmark 1974, Stephens 1984, and Thrupp 1990).

Extensive agricultural research on banana points to a diverse suite of pests considered to be of economic importance. Some research points to the biological control mechanisms attacking those pests in banana. Ostmark's (1974) comprehensive literature review identified 470 species of mites and insects that have been found to be major pests of bananas worldwide. Harrison (1963b) examined naturally occurring biological control 
of Lepidoptera throughout the year and found that lizards, spiders, dipteran, and hymenopteran fauna significantly reduced lepidopteran pest populations in banana plantations. This research was designed to assess seasonal variation in banana plantations and lepidopteran abundance, as well as the effect of plantation management practices on these organisms.

\section{METHODS}

\section{Study Site}

Six banana plantations, located in the Atlantic zone of Eastern Costa Rica, were used for this survey (Table 3-1). The plantations were chosen for their relatively close proximity to one another $(<35 \mathrm{~km})$ and similar microclimates. The plantation area

\section{Table 3-1}

Study site plantations.

\begin{tabular}{|l|l|l|}
\hline PLANTATON & REGHON & INPUT LEVEL \\
\hline Banaranja & Pococi & Low \\
\hline Casa Verde & Pococi & High \\
\hline Guadalupe & Pococi & High \\
\hline Penjamo & Sarapiquí & Low \\
\hline Rebusca & Sarapiquí & High \\
\hline Yuca Tica & Pococi & Low \\
\hline
\end{tabular}

covered in the parasitoid survey contained a representative sample of the abundance and diversity of lepidoptera on a variety of banana plantations throughout Costa Rica's Atlantic zone. Four plantations were in the Pococi region and three were in the Sarapiqui region. Both were close to the Organization for Tropical Study's La Selva Biological Research Station, where all laboratory work was conducted (Figure 1-2). 


\section{Survey Design}

Three plantations were chosen as high-input, receiving three or more nematicide applications a year, or low-input, receiving less than three applications. To assess seasonal variation in parasitoid communities, repeated surveys were conducted on the six plantations for three months during the 2001 "wet" season (July, August, and September), and three months during the 2002 "dry" season (January, February, and March).

At the beginning of the study, transects were randomly selected for each plantation. Each transect was at least 50 meters from the plantation edge to minimize the edge effect, which has been shown to yield a higher percent of parasitism (Broadmann et al. 1997). Two people conducted sampling for three hours from approximately 7:00 A.M. to $10: 00$ A.M. Cooler morning hours were chosen because midday heat causes many lepidopterans to descend from canopy foliage to escape the higher temperatures (Dyer pers com 2001; Cubillo pers com 2001).

Transects were 20 meters wide and ran the complete length of the plantation, and adjacent transects were separated by 50 meters. To maximize the number of Lepidoptera collected, sampling was initially conducted along a transect for 15 minutes. If no Lepidoptera were found during the initial 15-minute search, researchers would move 50 meters down the transect to search for another 15 minutes. If lepidopterans were found, sampling continued in the area until 15 minutes had elapsed after the last larva was collected, at which point the researchers moved down the transect 50 meters, repeating this method throughout the three hours. This method was used to maximize the number 
of lepidopteran specimens. If a transect was completed before the three-hour sampling period terminated, sampling was continued along another predetermined random transect. Like previous research on banana, this research utilized the preexisting cable system (used for transportation of fruit to the packing plant) to assess distance along transects. All plantations in this study had cable systems with support structures every 10 meters, allowing researchers to follow exact distances along each transect.

\section{Data Collection}

Banana plants average 10-15 leaves at any time (Jones 2000). Because previous research (Manley 1985 and Harrison 1963b) found that caterpillars are most often found on the lower (older) leaves, this research confined caterpillar search to the bottom eight leaves (Manley 1985 and Harrison 1963b). The lowest extended leaf was counted as leaf number one, and examination for Lepidoptera continued up to leaf number eight. If a plant had fewer than eight leaves, all leaves were inspected. Censuses involved a complete inspection of every plant within each $50 \times 20$-meter swath sample area.

The lepidopteran species collected are well known and required no further taxonomic identification. The three caterpillars used to measure parasitoid abundance and diversity were Antichloris viridis (Family: Ctenuchidae), Caligo memnon (Family: Nymphalidae), and Opsiphanes tomarindi (Family: Nymphalidae). These three species were chosen because of their history as outbreak species in Costa Rica. The complete life cycle of $A$. viridis lasts $33-48$ days and includes four stages: five-six days as an egg, $16-$ 25 days as a larva (six-seven instars), eight-18 days as a pupa, and four-seven days as an 
adult (Wielmaker 1981). The complete life cycles of C. memnon and O. tamarindi are similar, lasting 74-117 days and including four stages: eight-nine days as an egg, 37-49 days as a larva (five instars), 11-14 days as a pupa, and 18-45 days as an adult (DeVries 1987 and Harrison 1963).

To document Lepidoptera diversity on plantations, all lepidopteran species found were collected and recorded. All larvae collected were placed in collection bags and marked with the date and plantation name before being brought back to the laboratory for taxonomic identification and rearing. Only larvae were included in the lepidopteran survey; eggs, pupae, and adult lepidopteran data were not recorded.

To assess parasitism, each collected larva, plantation, caterpillar species, transect, and sample date were recorded. Collected larvae were placed in sealed plastic bags, labeled, and taken to the ambient laboratory at La Selva for rearing. The Lepidoptera/parasitoid rearing protocols used were those currently employed by Dyer at La Selva and Janzen and Hallwachs in Guanacaste. In the ambient laboratory, each larva was supplied with fresh foliage until it either pupated or died. If a larva pupated it was recorded as not being parasitized. If a larva died and a parasitoid emerged, it was recorded as parasitized, and the specimen was stored in the freezer, using the same bag, until the parasitoid was identified. If a larva died but no parasitoid emerged, the caterpillar was autopsied to determine whether parasitism was the cause of death. To prevent the transmission of pathogens, bags were only used once.

Functional biological control was documented by: (1) recording field densities of A. viridis, $O$. tamarindi, and $C$. memnon, in banana plantations under two types of pest 
management (three plantations with "low" pesticide inputs and three with "high," or conventional, commercial pesticide regimes), (2) collecting larvae in the field and rearing out the attacking parasitoids in the laboratory, and (3) synthesizing the data from (1) and (2) into a portrait of the populations of both hosts and parasitoid populations under different pesticide input conditions.

\section{Data Analysis}

In accordance with Lepidoptera and parasitoid research methods in the wet tropics, Lepidoptera that did not reach adulthood or become parasitized were eliminated (Dyer pers com 2001). The final analysis focused on $A$. viridis, C. memnon, and $O$. tamarindi, all historically important defoliators in Costa Rica. Lepidoptera and parasitoid abundances were measures using a repeated-measures ANOVA model. Plantation input levels (high-input/low-input) were contrasted against seasons (wet and dry), and the following dependant herbivore and parasitoid variables: total percent parasitism, percent Dipteran parasitism, percent hymenopteran parasitism, percent total parasitism on $A$. viridis, percent Dipteran parasitism on $A$. viridis, percent hymenopteran parasitism on $A$. viridis, total percent parasitism on $C$. memmon, percent Dipteran parasitism on $C$. memnon, percent hymenopteran parasitism on $C$. memnon, total percent parasitism on $O$. tamarindi, percent Dipteran parasitism on O. tamarindi, and percent hymenopteran parasitism on 0 . tamarindi.

Pearson's correlation coefficient was used to investigate correlations among parasitoid factors. Inverse correlations among parasitoids were explored for evidence of 
competition between species, or hyperparasitism. The following factors were examined: Hymenoptera (high-and low-input) and Diptera (high-and low-input), Brachimeria and all other parasitoids, Brachimeria and Diptera, Brachimeria and Eulophidae, Diptera and Eulophidae, and Braconidae and Diptera.

\section{RESULTS}

\section{Lepidopteran}

In this analysis a total of 1,095 Lepidoptera individuals were recorded as occurring in high-and low-input plantations. High-input plantations yielded a total of 545 total Lepidoptera individuals. The abundance of Lepidoptera in high-input plantations totaled 385 A. viridis, 126 C. memnon, and 34 O. tamarindi (Figure 3-1). Low-input plantations yielded a total of 550 Lepidoptera that either reached adulthood or were parasitized, including 307 A. viridis, 200 C. memnon, and 43 O. tamarindi (Figure 3-2).

Figure 3-1

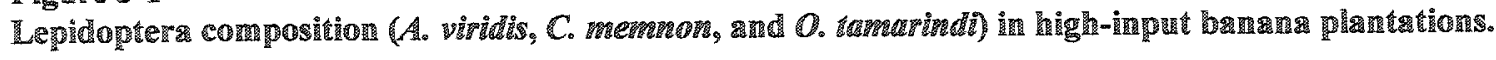

\section{Lepidopteræ Diversity in High-Imput} Plamtations

$$
\mathrm{n}=\mathbf{5 4 5}
$$

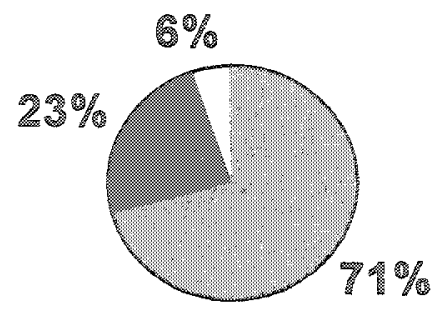

- A. Viridis

- C. memnon

口0. 
Figure 3-2

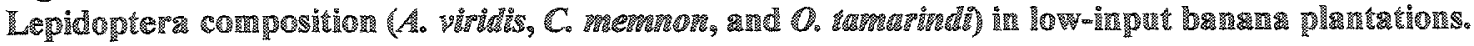

\section{Lepidoptera Diversity in Low-Imput \\ Plantations \\ $\mathrm{n}=5 \mathrm{~s} 0$}

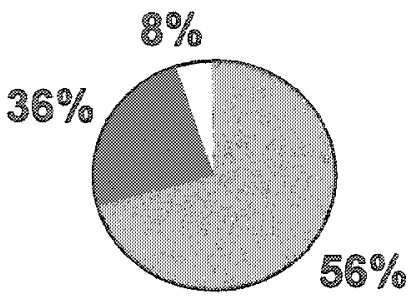

[D. Vindids

C. Memmon

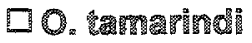

ANOVA repeated measures across seasons indicated no significant difference in lepidopteran abundance, for any of the three species, between input levels $(n=3)$.

Total lepidopteran abundance decreased significantly $(\mathrm{P}=0.030)$ from wet to dry seasons (Figure 3-3). Abundance of $A$. viridis $(\mathbb{P}=0.007)$ decreased significantly from wet to dry season (Figure 3-4). Conversely, total C. memnon (Figure 3-5) increased from wet to dry season $(\mathrm{P}=0.006)$. Abundance of $\mathrm{O}$. tamowind showed no significant decrease between wet and dry season abundance (Table 3-2).

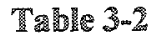

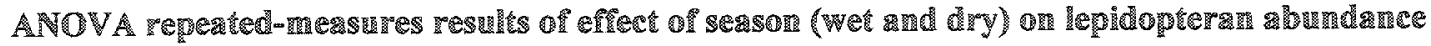

\begin{tabular}{|c|c|c|c|c|}
\hline Variation & MS & d. 1 & $F$ & $\mathrm{P}$ \\
\hline Total Lepioopteran abundance & 1012.677 & 1 & 7.904 & $0.030^{\circ}$ \\
\hline Abundance of $A$. viridis & 1020.593 & 1 & 25.832 & $0.007^{*}$ \\
\hline Abundance of $C$. memon & 116.148 & 1 & 27.752 & $0.006^{*}$ \\
\hline Abundance of C. memnon & 5.787 & 1 & 3.189 & 0.149 \\
\hline
\end{tabular}

* significant at the 0.05 level, ${ }^{\text {t }}$ possible trend 
Figure 3-3

Mean total lepidopteran abundwec in high and low-inpat banana plantations.

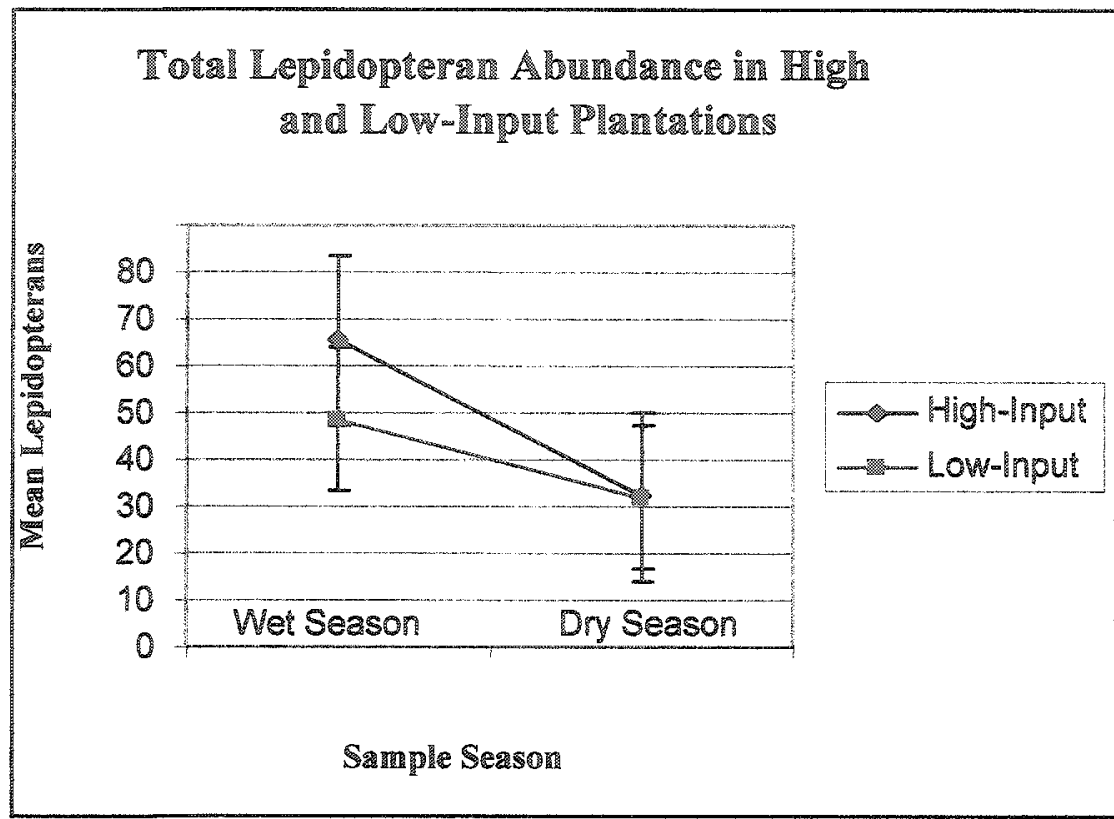

Figme 3-4

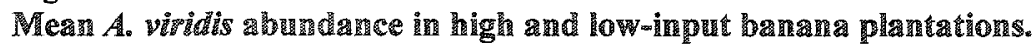

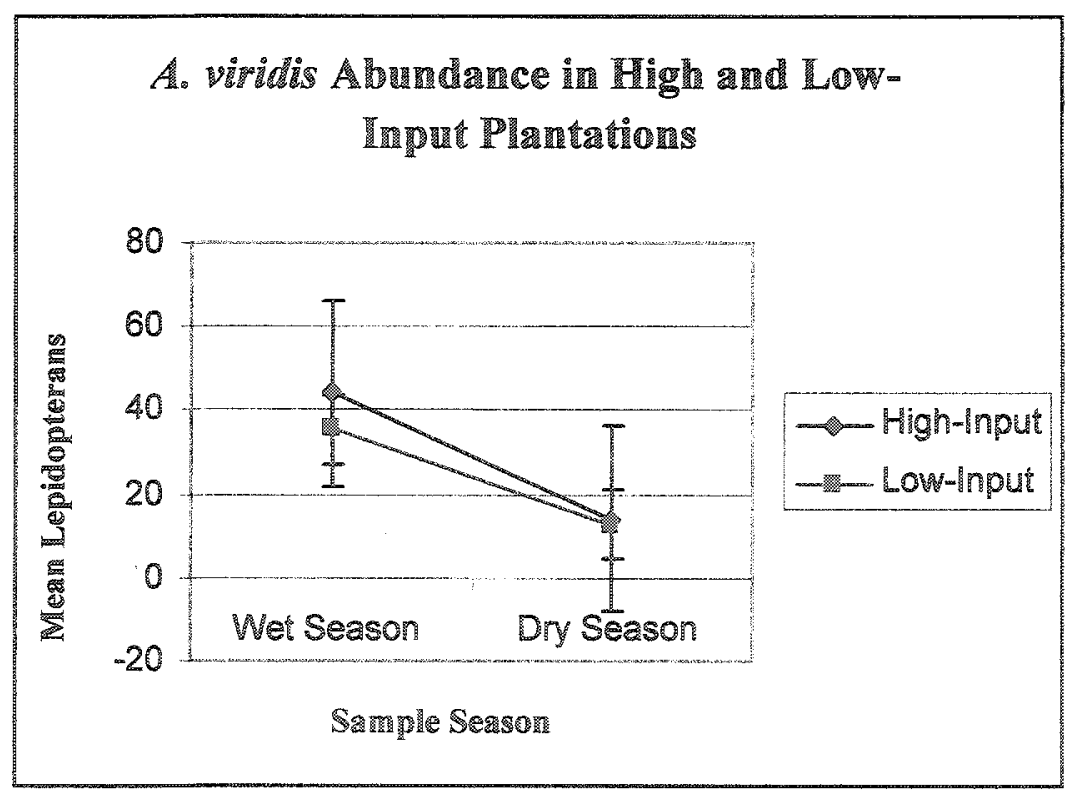


Figure $3-5$

Mean C. meweren abundance in high and how-input banana plantations.

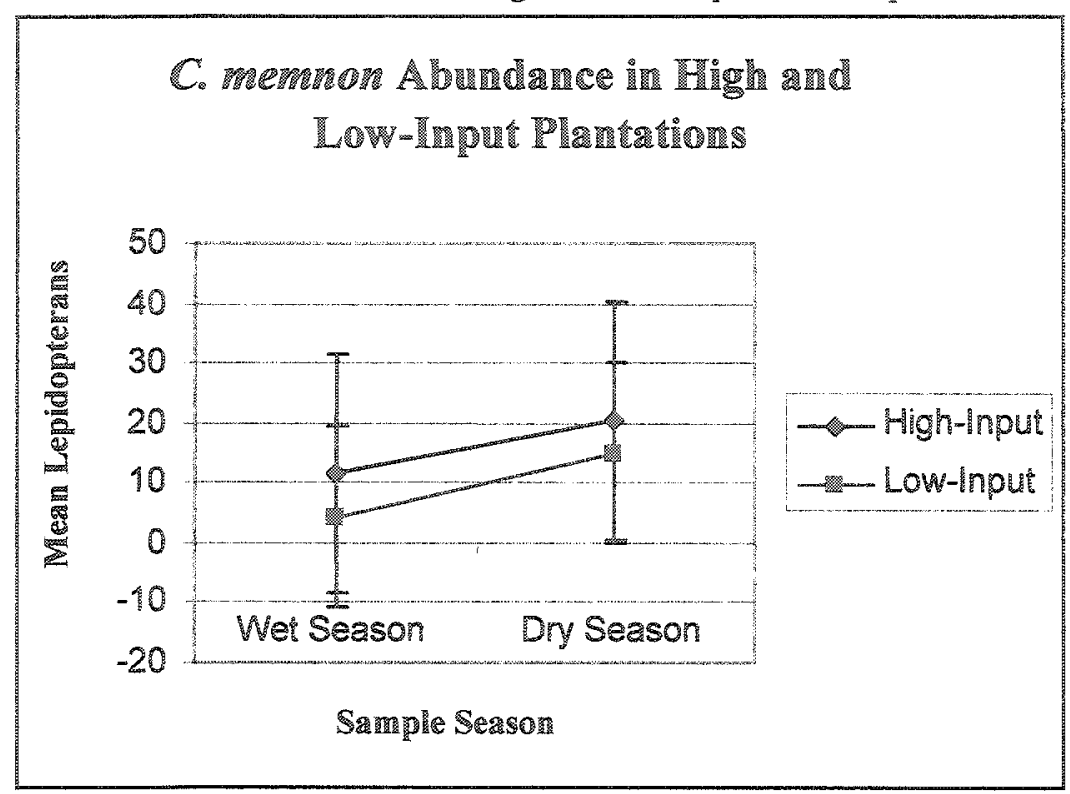

The seasonal variation did not affect parasitism in high-input or low-input plantations. Although, parasitoid levels were found to be almost always higher during the wet season, this is most likely the result of the higher host Lepidoptera populations during this time.

A total of 680 individual A. viridis, 319 C. memnon, and 62 O. tamarindi larvae were reared during the course of this study. Parasitoids, which totaled 232 , were composed of six species, and found to attack these three species of Lepidoptera. These parasitoids inchded both tachinid hies and several genera of parasitic hymenoptera.

\section{Parasitism}

In low-input plantations Lespesia aletiae (Tachinidae) constituted the highest number of parasitoids $(66 \%)$ attacking $A$. viridis in the field, followed by the parasitic wasps Meteorus laphygmae (Braconidae), Elachertus sp. (Eulophidae) and Brachymeria 
comitator (Chalcididae) (Figure 3-6). On low-input plantations, A. viridis was attacked most by M. laphygmae (52\%), followed by L. aletiae, Elachertus sp., B. comitator,

Cotesia sp. and Blepharia sp. (Tachinidae) (Figure 3-7).

Figure 3-6

Parasitoid diversity on $A$. wirduls in high-ipput banana plantations.

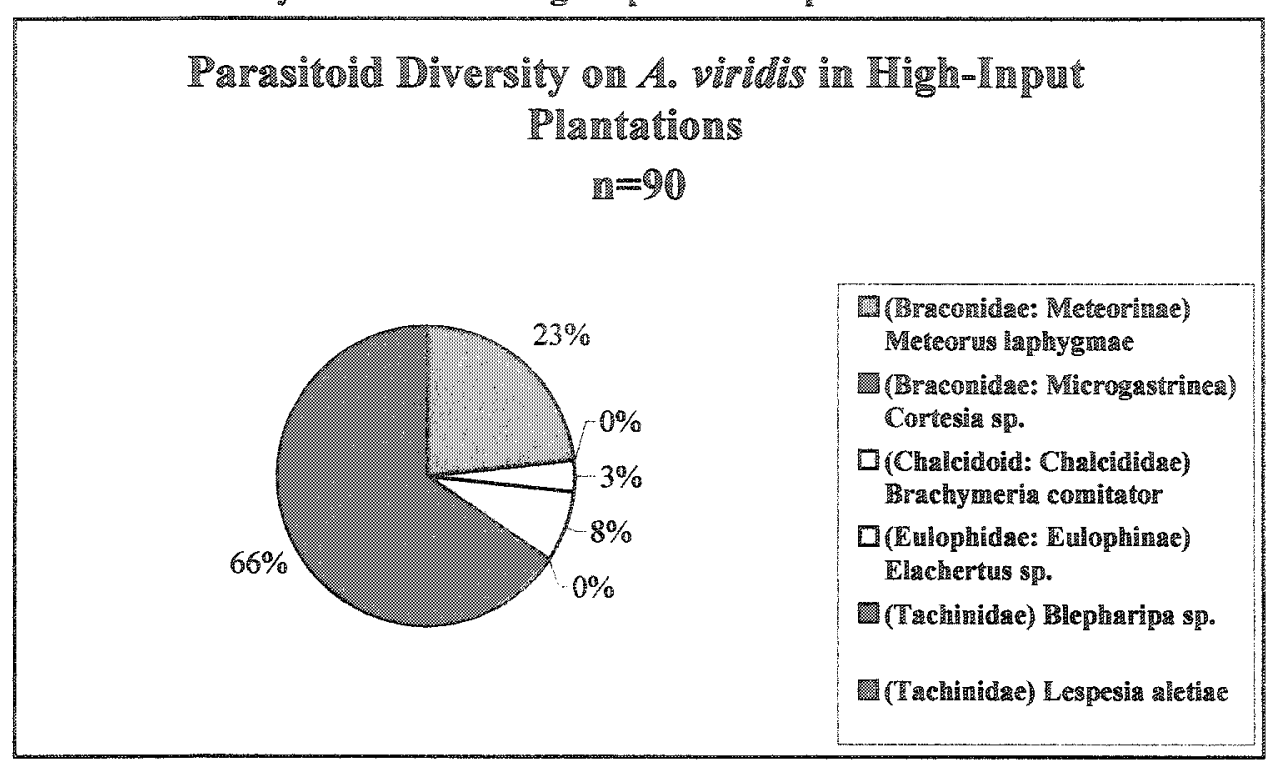

Figure 3-7

Parasitoid diversity on $A$. wizidis in low-impar banana plantations.

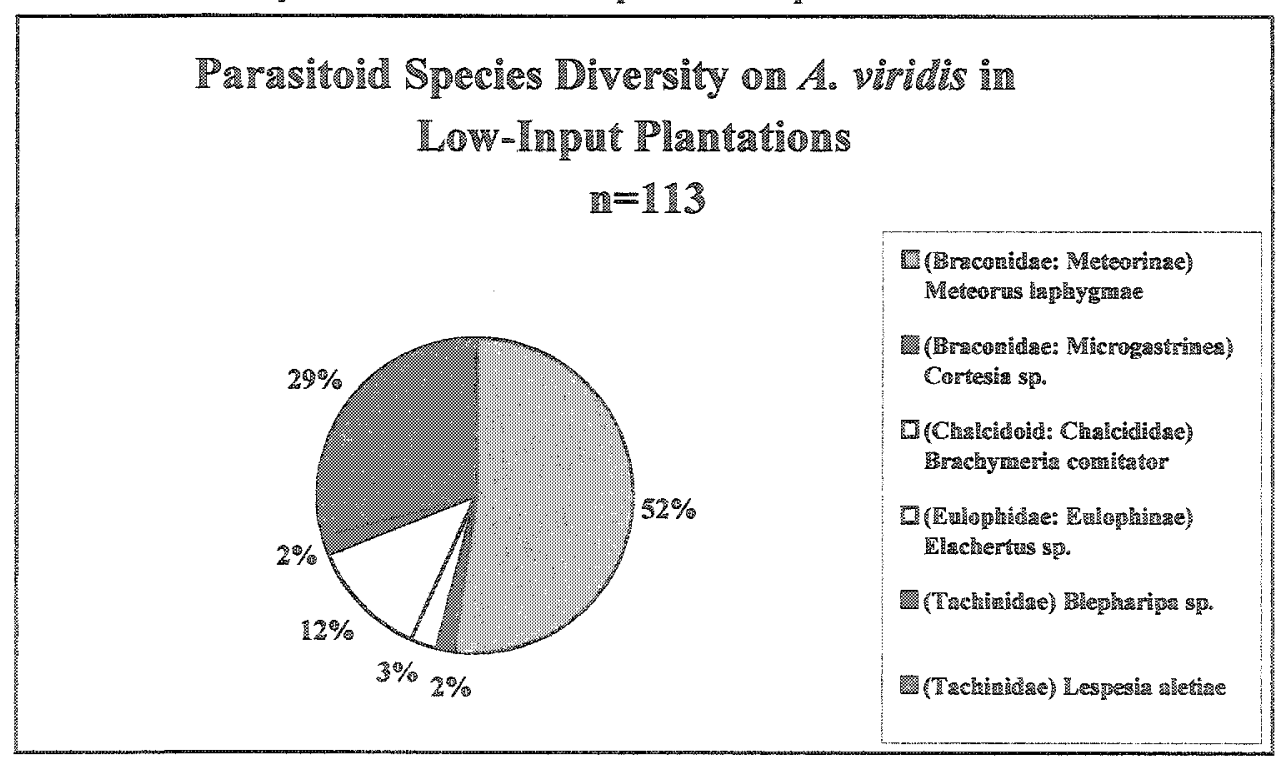


The tachinid fy, L. aletiae, constituted the highest number of parasitoids (50\%) attacking $C$. memon in high-imput plantations, followed by $B$. comitator and Blephoria sp. (Figure 3-8). On low-input plantations, $75 \%$ of the parasitoids attacking $C$. memnon were the tachinid fly $L$. aletioe, and the remaining $25 \%$ were attacked by $M$. lophygmoe (Figure 3-9). 
Figure 3-8

Parasitoid diversity on C. meman in highwinput bamana plantations.

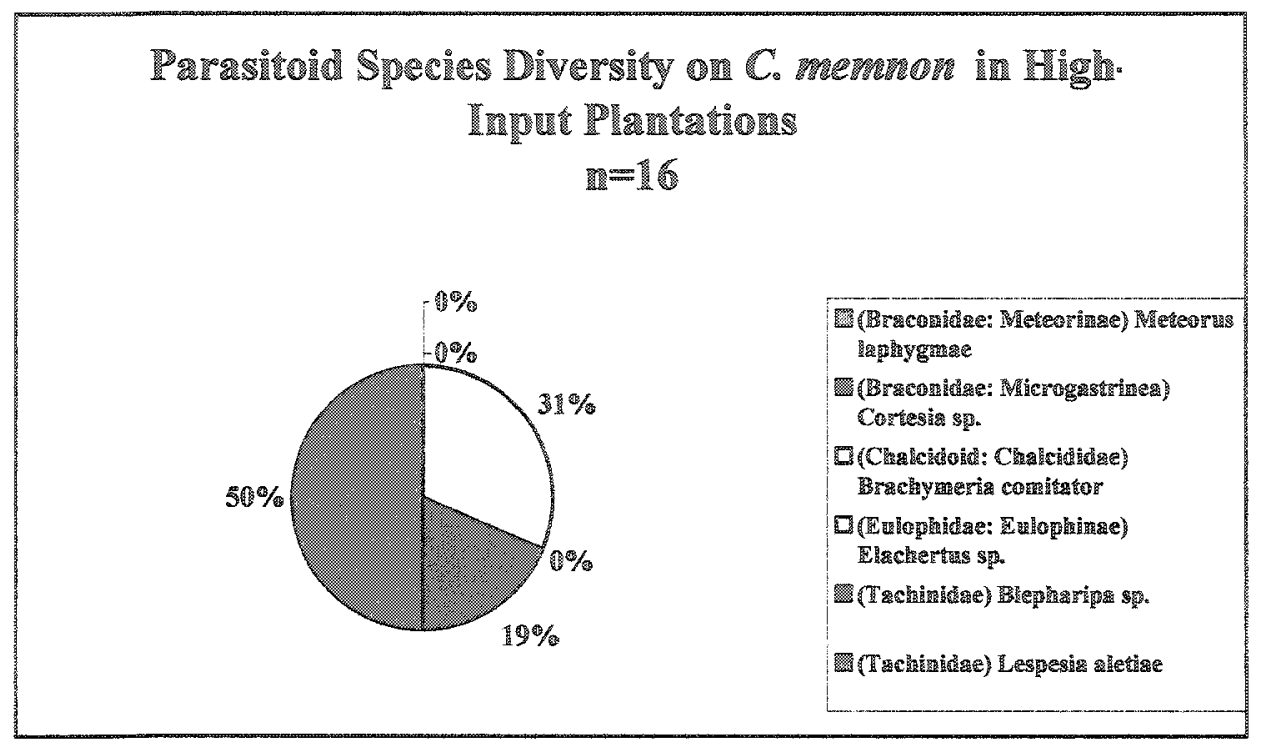

Figure 3-9

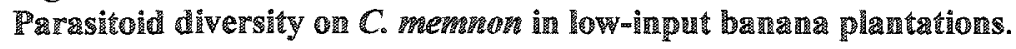

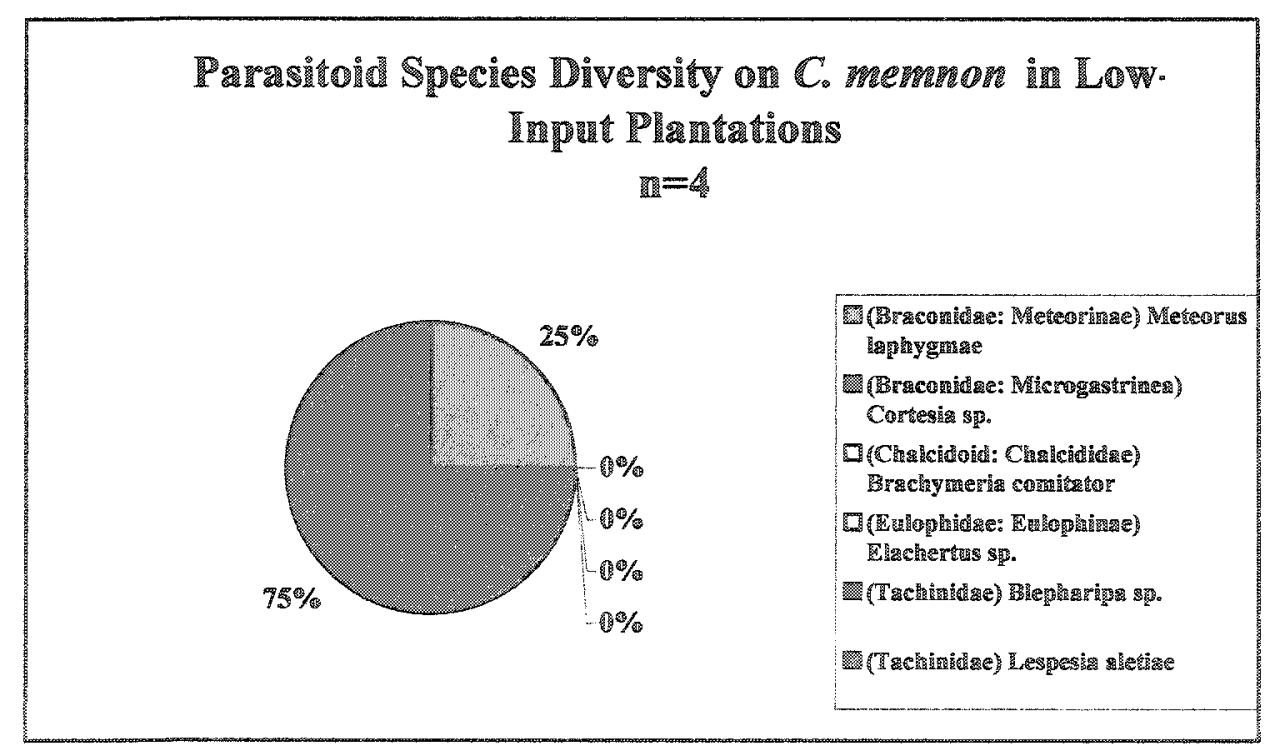

On high-input plantations 0 . tamorindi was atacked by $L$ aletioe $(75 \%)$ and by $M$.

laphygmae (25\%) (Figure 3-10). In low-input plantations $L$. aletiae constituted the 
highest number of parasitoids (60\%) attacking O. tamarindi, followed by B. comitator and M. laphygma (Figure 3-11).

Tige $3-10$

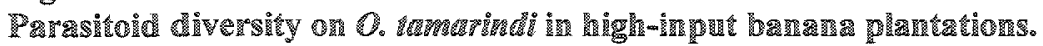

Parasitoid Species Diversity on O. tamarindi in High. Imput Plantations

$\mathrm{m}=4$

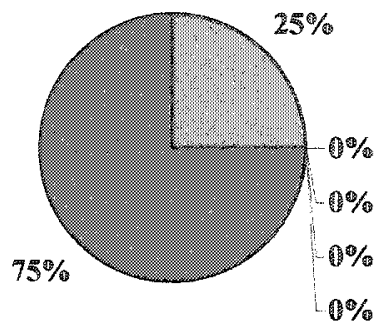

Y (Bracoli

Meter

20 (Bracona Cortesing sho.

D(Chalcidoid: Chaicidurae)

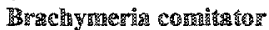

PI (E⿱

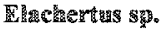

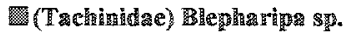

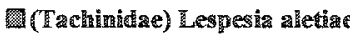

Figure 3-1 1

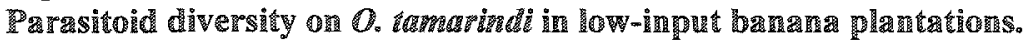

\section{Parasitoid Diversity on O. tamarindi in Low} Input $P$ lantations $1=5$

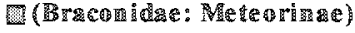

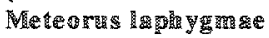

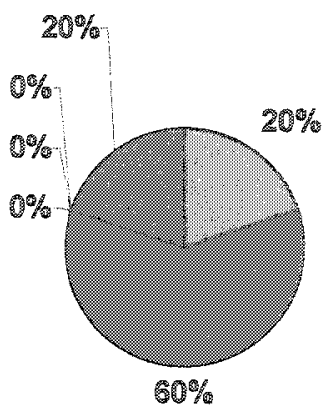

急

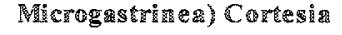
$\$$ ip.

D(Chalchold: Chalcidida) Reck y

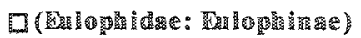

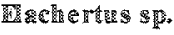

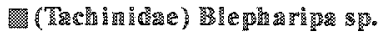

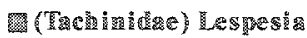
âtertio 
Repeated-measures ANOVA analysis indicates that total percent parasitism did differ significantly $(\mathrm{p}=0.011)$ between high-input (19.49\%) and low-input (8.33\%) plantation pesticide levels. ANOVA analysis also indicated a significant $(p=0.048)$ total parasitism on 0. tamarindi high (32\%) and low-input (55.56\%) plantations (Table $3-3$ and Figure 3-12).

The 3-3

ANOVA repeated-measures results of eflect of pesticide level (high-input and low-input) on percent parasîtism.

\begin{tabular}{llll}
\hline Variation & d.f. & F & P \\
\hline Total parasitism & 1 & 20.009 & $0.011^{*}$ \\
Dipteran parasitism & 1 & 0.370 & $0.080^{\mathrm{z}}$ \\
Total parasitism on C. memnon & 1 & 6.335 & $0.066^{\mathrm{*}}$ \\
Total parasitism on O. tamarindi & 1 & 7.904 & $0.048^{*}$ \\
\hline
\end{tabular}

* significant at the 0.05 level, "possible trend

Figure 3-12

Parasitold abundance in high and low-inpupt plantations.

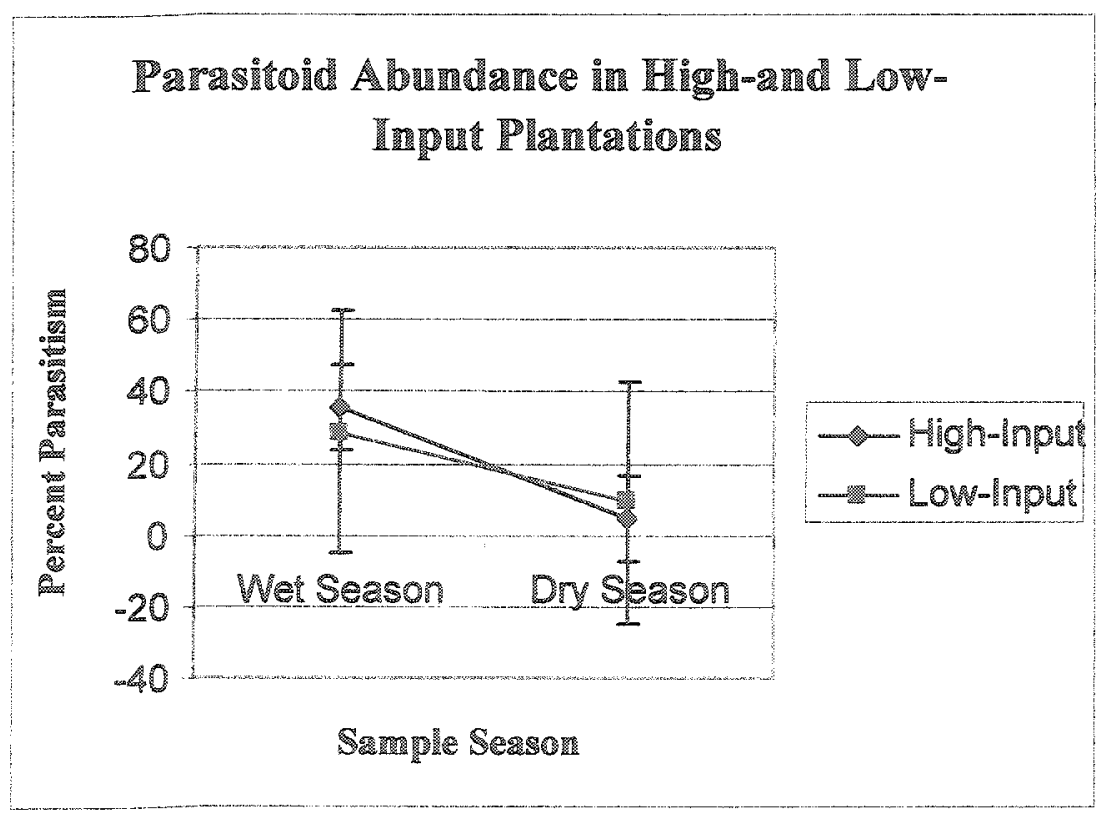


At $p=0.080$, dipteran parasitism indicates a trend towards a significant difference between high-input $(66.36 \%)$ and low-input (33.64\%) plantations (Figure 3-13). 0. tomarindi also was significantly different among high-input (21.78\%) and low-input (12.04\%) plantations (Figure 3-14), although the low number of $O$. tamarindi $(n=9)$ yields a very low statistical power. Also, $p=0.066$ indicates a trend of increased total dipteran parasitism of $C$. memnon in high-input (19.83\%) versus low-input $(7.36 \%)$ pesticide levels.

Figure 3-13

Dipterar abundance in high and low-irnput plantations.

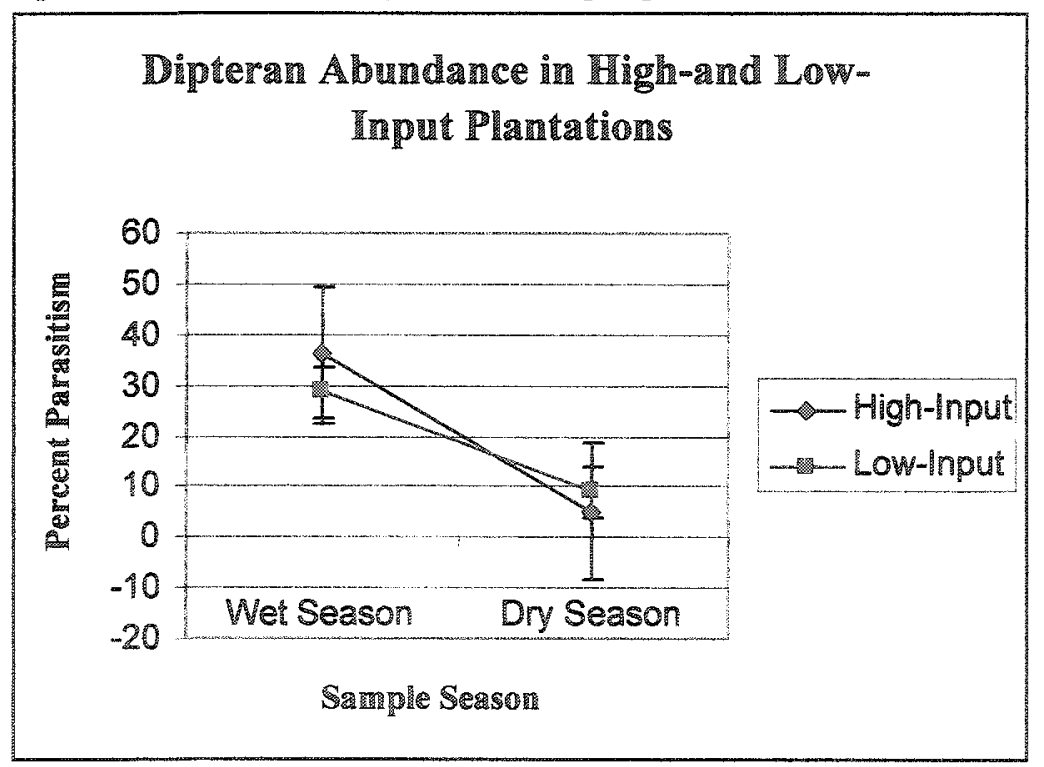


Figure 3-14

Total Percent Parasitism on C. memon in High and Low-imput Plantations.

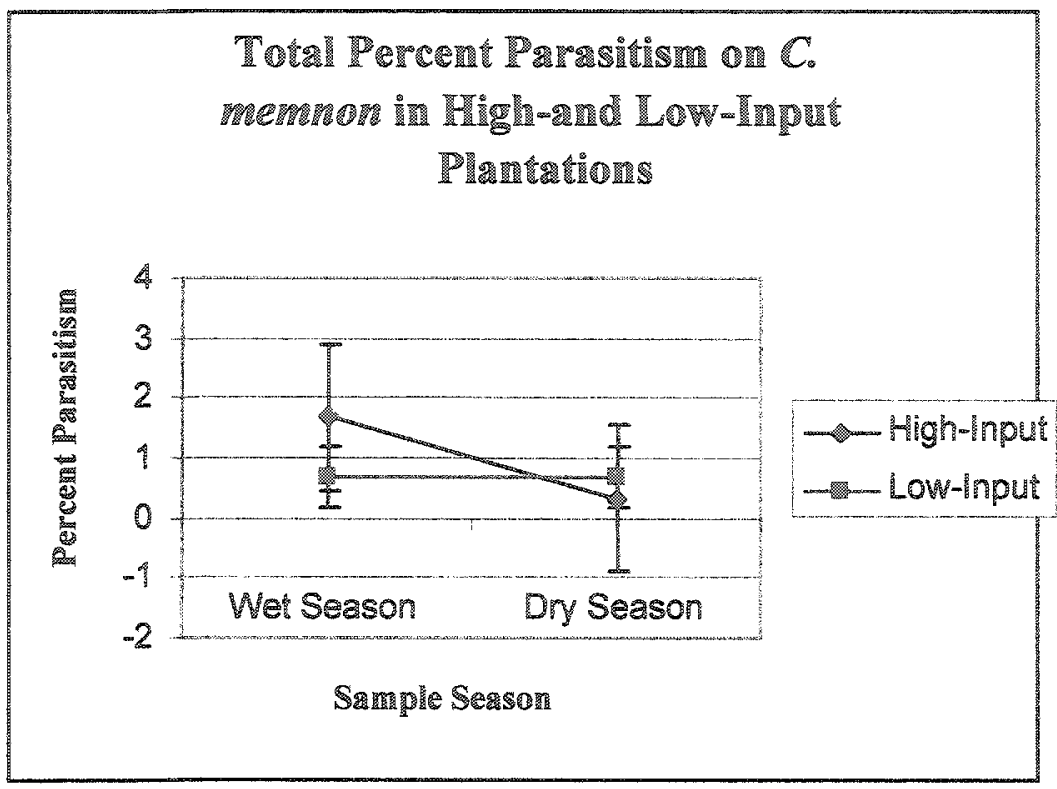

A significant positive correlation was found between the abundance of Hymenopteran and Dipteran parasitoids in both high-imput and low-input plantations and in only low-input plantations (Table 3-4).

Tale 3-4

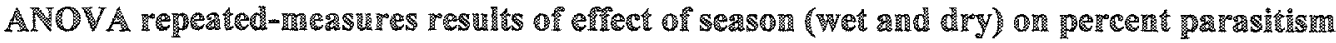

\begin{tabular}{llll}
\hline Variation & d.f. & F & P \\
\hline & & & \\
Dipteran parasitism & 1 & 4.987 & $0.089^{1}$ \\
Total parasitism on C. memnon & 1 & 6.355 & $0.066^{\mathbf{1}}$ \\
\hline
\end{tabular}

* significant at the 0.05 level, "possible trend

Hymenopteran and Dipteran parasitism was positively correlated, indicating that among farm types, parasitism levels tracked one another (Table 3-5). This was not as true in high-input plantations, where there was no correlation between Dipteran families. However, in low-input plantations there was a strong correlation among parasitoid 
families. These correlations reinforce the earlier findings that Dipteran are the dominant parasitoid in high-input level plantations. Brachimeria parasitoids were found to positively correlate with all other parasitoids. A possible trend $(p=0.067)$ indicates a positive correlation between Brachimeria and Diptera populations.

The lack of significant negative correlations between any of these groups of parasitoids indicates that competition and hyperparisitsm are not strong factors among these parasitoids attacking the three outbreak hosts. Similarly, laboratory examination of parasitoids yielded no cases of hyperparisitsm.

Table 3-5

Pearson's correlation coefficient analysis of parasitoid abundance.

\begin{tabular}{llll}
\hline Variables & $\mathrm{N}$ & Sig. (2-tailed) & Pearsons Corr. \\
\hline $\begin{array}{l}\text { Hymenoptera-Diptera } \\
\text { (high-and low-input) }\end{array}$ & 106 & $0.003^{*}$ & 0.288 \\
$\begin{array}{l}\text { Hymenoptera-Diptera } \\
\text { (high-input) }\end{array}$ & 54 & 0.392 & 0.119 \\
$\begin{array}{l}\text { Hymenoptera-Diptera } \\
\text { (low-input) }\end{array}$ & 54 & $0.000^{*}$ & 0.673 \\
$\begin{array}{l}\text { Brachymeria-all other } \\
\text { parasitoids }\end{array}$ & 6 & $0.000^{*}$ & 0.986 \\
$\begin{array}{l}\text { Brachymeria-Diptera } \\
\text { Brachymeria-Eulophidae }\end{array}$ & 6 & $0.067^{*}$ & 0.781 \\
Diptera-Eulophidae & 6 & 0.185 & 0.625 \\
Braconidae-Diptera & 6 & 0.950 & -0.033 \\
\hline *correlation is significant at the 0.01 level, & $60 s s i b l e$ trend & 0.181 \\
\hline
\end{tabular}




\section{DISCUSSION}

More than half of all lepidopteran collected in this study (63.20\%) were A. viridis. The high abundance (692) of A. viridis collected in this study is consistent with past studies of $A$. viridis as a primary outbreak species of banana in Costa Rica as well as present research into abundance of lepidopteran in Costa Rican plantations (Cubillo pers com 2001, Lara 1970, Ostmark 1974, and Stephens 1984). The high abundance of $A$. viridis, and C. memnon (29.77\%) suggests that these pest species of previous economic importance do still potentially pose a threat to banana farming in the regions. Unlike $A$. viridis and C. memnon, O. tamarindi (7.03\%) do not appear to be significant defoliators of banana in the regions. These conclusions are supported by banana farmers in the region.

These lepidopteran outbreak species that occurred from 1950-1973 are subject to seasonal fluctuations in banana plantations. This is especially true for populations of $A$. viridis and C. memnon. Populations of these same species do not fluctuate in the nearby forests (Dyer pers com 2001). Given that A. viridis still exists in high numbers throughout the plantations in this study, it can be hypothesized that $A$. viridis will most likely emerge as an economically important pest once again during a prolonged wet season. The phenomenon of reduced lepidopteran populations on banana plantations during the dry season indicates that $A$. viridis and $C$. memnon are less likely to inhabit hot and dry plantations. Cultural practices, such as removing older leaves on plants, may contribute to a more arid plantation and therefore contribute to lower levels of $A$. viridis and C. momnon. O.tamarindi, however, may be less influenced by these factors. 
Decline in Lepidoptera abundance in the forests of Costa Rica's Atlantic zone is believed to be uncommon, and abundance is considered relatively static throughout the year (Dyer pers com 2001). However, the decline in Lepidoptera abundance in banana plantations during the dry season is widely accepted by farmers and researchers in the area. This decline is attributed to the lack of a forest canopy, which leads to higher-thanusual heat and lower rainfall on the banana plantations (Cubillo pers com 2001).

These three species of lepidopteran do not appear to be influenced by pesticide input levels on plantations. Of the three species, the abundance of $O$. tamarindi, abundance did indicate a possible trend of lower abundance in high-input plantations. The factors affecting this trend may be (1) O. tamarindi is more susceptible to the pesticides used on plantations, or (2) tachinids, which are more abundant in high-input plantations, play a significant role in $O$. tamarindi mortality.

Although varying amounts of nematicides and chlorypyrifos-impregnated bags were used on the plantations, the lack of significant population response to these variables suggests that the previous outbreak species may (1) have developed resistance to these commonly used plantation chemicals or (2) not be affected by the residual amounts of pesticide that may occur on the plant foliage.

Currently, when lepidopteran levels begin to rise, a common practice among banana plantation managers is to begin to rotate the pesticides that are used on plantations (Cubillo pers com 2001). The apparent success of this practice, combined with the understanding that the lepidopteran are not themselves affected by chemical levels, indicates that this practice may be affecting beneficial parasitoid levels. 
As has been hypothesized for years, these previous outbreak species appear to be regulated by the naturally occurring parasitoid community in Costa Rica. A. viridis was the species that experienced the highest levels of parasitism (19.80\%), followed by $O$. tomarindi (13.04\%) and C. memnon (12.83\%). Parasitism of A. viridis is approaching potentially effective biological control levels as described by Hawkins et al. (1993). Hawkins (1994) asserts that to draw the conclusion that a host is successfully controlled by parasitoids with a high degree of certainty requires additional research into numerous biological variables, such as hyper parasitoid richness and host parasitism by generation. An experiment involving the placement of artificially reared pest species would better gauge levels of biological control. The level of parasitism observed in this study, though not spectacular by biological control standards, does indicate some success of the naturally occurring parasitoids at augmenting former outbreak species of Lepidoptera (Hawkins 1994).

Total proportion of parasitism was significantly $(\mathrm{p}=0.011)$ higher in high-input $(58.43 \%)$ versus low-input plantations (41.56\%). Though not significantly different, the abundance of parasitic Hymenoptera was lower in high-input (46.20\%) verses low-input (53.80\%) pesticide plantations. The opposite pattern was found for dipteran parasitoids; $66.53 \%$ of the dipteran parasitism occurred in high-input and $33.47 \%$ in low-input pesticide plantations. Because tachinids were the most important source of lepidopteran mortality, overall parasitism was higher in high-input (20.27\%) versus in low-input (10.17\%) plantations. This data indicates that dipteran parasitoids may be able to withstand higher levels of pesticides than Hymenoptera in low-input plantations. Higher 
levels of hymenopteran parasitism in low-input plantations indicates that hymenopteran parasitoids are more effective than Diptera at controlling Lepidoptera. These same Hymenoptera are less successful in the dipteran abundant higher-input plantations.

Total parasitism of $O$. tamarindi was significantly higher in high-input plantations $(55.56 \%)$ versus low-input plantations (44.44\%). A similar trend $(\mathrm{p}=0.066)$ occurred with total parasitism on C. memnon on high-input (7.78\%) versus low-input $(22.22 \%)$. Both of these large Noctuidae species were more parasitized on those plantations with a higher number of dipteran parasitoids. The large larva size of these two species, as compared to A. viridis, may be preferred by dipteran parasitoids. Conversely, in lowinput plantations $A$. viridis is parasitized by more hymenopteran (68.04\%) parasitoids than dipteran parasitoids (33.64\%). Hymenopteran parasitoids are more successful at parasitizing $A$. viridis than the $C$. memnon or $O$. tamarindi. This may point to more of a hymenopteran specialization on the smaller, but more abundant, $A$. viridis.

Obtaining specific pesticide regime information proved more difficult than originally anticipated. It was not possible to obtain detailed information, such as specific pesticides used and application rates. Therefore, a simple high-input vs. low-input categorization was analyzed. More controlled research would yield parasitoid susceptibility to specific chemicals.

The final two sampling months showed drastic declines in lepidopteran and parasitoid abundance and diversity. The months of February and March are the beginning of the dry season in Costa Rica. This seasonal decrease has been recognized by banana farmers in Costa Rica for many years (Cubillo pers com 2001). More 
extensive experimentation could test for those factors causing cyclical lepidopteran decline in plantations. 


\section{CHAPTER 3: THE EFFECT OF INTERCROPPING ON LEPIDOPTERAN AND PARASITOID LEVELS}

\section{INTRODUCTION}

Many studies have demonstrated the benefits of enhancing parasitism through the incorporation of a nectar source into an agricultural system. Although banana agroecosystems are typically diverse and often cited as "natural-system" mimics, studies have integrated the effects of intercropping a monoculture plantation with a nectar source to enhance parasitism.

Parasitoids feed primarily on floral nectar, extrafloral nectar, and insect honeydew, with some taxa feeding on host insect hemolymph (Idris and Grafius 1995). The nutritional requirements of most parasitoids are met through the parasitoid ingestion of three primary nectar sugars: glucose, fructose, and sucrose (Hagen et al. 1984 and Kevan and Baker 1984). Patt (1997) states that intercropping with nectar sources can suppress pest levels by increasing parasitoid survivorship, fecundity, and retention. Idris and Grafius (1995) tested the nutritional effectiveness of 14 wildflowers and found that the nutritional content of nectar played a significant role in increasing the longevity and fecundity of parasitoids.

As a follow-up to their previous study, Idris and Grafius (1997) examined the correlation between behavior, floral structure characteristics, and floral preference, finding no preference for flower color among eight species tested (seven Brassicaceae and one Umbelliferae) and wide behavioral flexibility with respect to flower structure. 
Pemberton and Lee (1996) found a correlation between four plant species with extrafloral nectaries (Populus seiboldii, Populus hybrid, Prunus persica, Prumus leveilleana, and Robinia pseudoacacia) and parasitism of Lymantria dispar (gypsy moth) on Quercus sp. in South Korea. The primary parasitoids attracted in Pemberton and Lee's (1996) study were Braconidae, Ichneumonidae, and Tachinidae.

Lewis et al. (1990) discussed the foraging behavior of parasitoids and the plasticity of host foraging. Using visual, tactile, and chemical stimuli, parasitoids constantly modify their behavior to increase their likelihood of success in nectar searching behavior. This ability to modify searching behavior helps support experiment design, such as this one, that attempt to increase parasitoid presence in areas with more floral and extrafloral nectar.

Powell (1986) provides a comprehensive overview of the use and monitoring of beneficial insects in agroecosystems, documenting that introducing a food source can be a successful method for improving parasitoid effectiveness. In a related article, Patt et al. (1999) studied the ability of parasitoids to adapt to new food sources and showed that parasitic Hymenoptera leam to recognize a food source after a new feeding experience.

Joseph et al. (1997) found that flower utilization by parasitoids depended on the floral architecture, with nectar foraging decreasing as nectar inaccessibility increased. Joseph et al. tested a large variety of plants in their intercropping experiment and found that flowers with exposed or partially exposed nectar received the largest percent of nectaring time by parasitoids. 
The leguminous genus Flemingia has a natural range from the humid to subhumid tropics of Southern and Southeastem Asia. A native to Asia, Femingia was naturalized in Africa as well as Central and South America (CIAT 2001 and Hui-Lin Li 1944). F. macrophylla is used primarily as a forage crop and/or for erosion control. $F$. macrophylla is well suited to the banana plantations of Costa Rica's Atlantic zone, preferring intermediate to low fertility soils, moderate to high rainfall, and shade (Andersson, Schultze-Kraft, and Peters 2002). F. macrophylla produces both floral and extrafloral nectar and had been rumored to attract a wide variety of Dipteran and hymenopteran parasitoids in Central American agroecosystems (Cubillo pers com 2001).

The initial selection criteria for plants in this experiment were (1) the plant must have been able to grow well in the low-light understory of banana plantations, (2) the flower species is perennial, (3) the species was native, and relatively abundant throughout Costa Rica, and (4) the plant must have been reasonably inexpensive by local standards and thus accessible to most farmers. F. macrophylla meets these criteria. In addition, the plant has been researched at numerous independent conventional plantations throughout Costa Rica, primarily as an erosion control measure. Therefore, use of $F$. macrophylla in this experiment had the benefit that it was already accepted by farmers as beneficial in conventional farming techniques. This experiment was designed to test whether incorporating a nectar source into a conventionally managed banana agroecosystem augmented beneficial parasitoid populations. For this study, the effects of intercropping on parasitism of Lepidoptera in areas in a banana plantation that were intercropped with a 
known nectar source were compared to areas of a plantation not intercropped with a nectar source.

\section{METHODS}

\section{Study Design}

A plantation located at the Escuela de Agricultura de la Region Tropical Humida (EARTH) in Costa Rica, employing Flemingia macrophylla as a means of erosion control and protection of canals from pesticide pollution, allowed study of the effects this nectar producing plant.

Areas intercropped had all canals covered with $F$. macrophylla; these canals ranged from one to three meters wide and were located throughout the intercropped sample area. Two distinctly different areas were sampled: (1) banana plants that were within 50 meters of $F$. macrophyllo and (2) banana plants that were located more than 50 meters from $F$. macrophylla plants. Each sample consisted of 10 plants along a random transect.

Similar to the parasitoid survey in Chapter 2 , this study involved: (1) collecting $A$. viridis, $O$. tamarindi, and C. memnon larvae, (2) rearing the attacking parasitoids from caterpillars in the laboratory, and (3) synthesizing the data from (1) and (2) into a portrait of the populations of both hosts and parasitoid populations under conventional and intercropped systems. This experiment was designed to test for differences in abundance and diversity of Lepidoptera and levels of parasitism among treatments. 


\section{Data Collection}

Collection, rearing, and recording methods were the same as those used in the parasitoid survey (Chapter 2). To document Lepidoptera diversity on plantations, all lepidopteran species found were collected and recorded. All larvae collected were placed in collection bags and marked with the date and plantation name before being brought back to the laboratory for taxonomic identification and rearing. Only larvae were included in the lepidopteran survey; eggs, pupae, and adult lepidopteran data were not recorded.

To assess parasitism, each collected larva, plantation, caterpillar species, transect, and sample date were recorded. Collected larvae were placed in sealed plastic bags, labeled, and taken to the ambient laboratory at La Selva for rearing. The Lepidoptera/parasitoid rearing protocols used were those currently employed by Dyer at La Selva and Janzen and Hallwachs in Guanacaste. In the ambient laboratory, each larva was supplied with fresh foliage until it either pupated or died. If a larva pupated it was recorded as not being parasitized. If a larva died and a parasitoid emerged, it was recorded as parasitized, and the specimen was stored in the freezer, using the same bag, until the parasitoid was identified. If a larva died but no parasitoid emerged, the caterpillar was autopsied to determine whether parasitism was the cause of death. To prevent the transmission of pathogens, bags were only used once. Eleven intercropped and conventional sample quadrats were selected and sampled monthly for three months. Each sample quadrat (11 experiment and 11 control) consisted of 10 plants. Thus, 110 
plants were completely inspected for lepidopteran from the experimental and control transects each month.

\section{RESULTS}

A total of 62 Lepidoptera were collected in both the control and intercropped areas of the plantation. Of the 62 lepidopeteran collected, 58 were $A$. viridis, two $C$. memnon, and two O. tamarindi.

Parasitoid abundance was therefore extremely low during the three-month experiment. Five parasitoids were recorded parasitizing $A$. viridis, one parasitized $C$. memnon and none parasitized O. tamarindi. Three parasitoids (two Diptera, Tachinidae, Lepesia aletiae and one Eulophidae Eulophinae, Elachertus sp.) parasitized A. viridis in control areas. Two parasitoids (two Eulophidae Eulophinae, Elachertus sp.) were recorded parasitizing $A$. viridis in intercropped areas (Table 4-1). 
Table 4-1

Parasitism on lepidopteran in intereropped and control mreas.

\begin{tabular}{|c|c|c|}
\hline Variation & $\mathrm{N}$ & Species \\
\hline \multicolumn{3}{|l|}{ Parasilotds in intercropped areas: } \\
\hline Parasitism of $A_{0}$ viridis abundance & $\begin{array}{l}1 \\
1\end{array}$ & $\begin{array}{l}\text { Lepesia aletiae } \\
\text { Eulophidae Eulophinae, Elachertus sp. }\end{array}$ \\
\hline $\begin{array}{l}\text { Parasitism of } C \text {. memon abundance } \\
\text { Parasitism of } O \text {. tamarindi abundance }\end{array}$ & $\begin{array}{l}1 \\
0\end{array}$ & Lepesio aletiae \\
\hline \multicolumn{3}{|l|}{ Parasitoids in intercropped areas: } \\
\hline $\begin{array}{l}\text { Parasitism of } A \text {. viridis abundance } \\
\text { Parasitism of } C \text {. memron abundance } \\
\text { Parasitism of } O \text {. tamarindi abundance }\end{array}$ & $\begin{array}{l}2 \\
0 \\
0\end{array}$ & Eulophidae Eulophinae, Elacherius sp. \\
\hline
\end{tabular}

Overall lepidopteran abundance did not significantly differ between intercropped and conventional plantation areas. Similarly, none of the three Lepidoptera populations was significantly different between plantation types (Table 4-2).

\section{Table A}

Paired t-test results of effect of intercropping on lepidopteran abundance.

\begin{tabular}{llll}
\hline Variation & $\mathrm{t}$ & $\mathrm{d}$.f. & $\mathrm{P}$ \\
\hline Total lepidopteran abundance & 0.822 & 9 & 0.479 \\
A. viridis abundance & 0.489 & 9 & 0.673 \\
C. memmon abundance & 1.00 & 9 & 0.423 \\
O. tamarindi abundance & -1.00 & 2 & 0.423 \\
\hline
\end{tabular}

*significant at the 0.05 level

Parasitism also did not differ between plantation types. Similar to the findings for Lepidoptera abundance, this experiment found no difference between any of the parasitism ractors (Table 4-3). 
Table 4

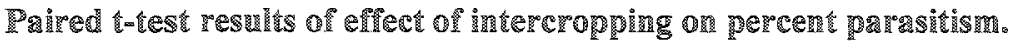

\begin{tabular}{llll}
\hline Variation & d & d.f & P \\
\hline Total parasitism & 0.192 & 2 & 0.866 \\
Parasitoid diversity & 0.50 & 2 & 0.667 \\
Total parasitism on A. viridis & 0.193 & 2 & 0.865 \\
Total parasitism on C. memnon & no data & - & - \\
Total parasitism on O. tamarindi & no data & - & - \\
\hline
\end{tabular}

*significant at the 0.05 level

\section{DISCUSSION}

Of the $58 \mathrm{~A}$. viridis collected during this experiment, 47 of these were early (first or second) instars, which are most susceptible to high mortality caused by environmental factors such as weather. Conversely, as caterpillar larvae increase in age, mortality due to environmental factors decreases while mortality due to natural enemies such as predators and parasitoids increases (Bradford, Howard, and Hochberg 1997). Mortality of these early instar caterpillars was high. Of the 47 early instar $A$. viridis collected, 34 $(72.34 \%)$ died in the ambient laboratory with no evidence of parasitism.

The low number of parasitoids (five) was not at all surprising given the low number of lepidopteran collected during this experiment. The likely reasons for the low levels of Lepidoptera collected are; (1) EARTH was not chosen for its high caterpillar levels (as were other survey plantations) and had lower overall abundance of lepidopteran (possibly as a result of being intercropped with a nectar source); (2) the searching methodology involved searching along a pre-set random transect, not utilizing a flexible searching method (as was done in the survey); (3) the number of sample transects was relatively low; (4) to reduce the spread and effect of the disease Black Sigatoka 
(Mycosphaerella fijiensis Morlet) on plant production, cultural practices at EARTH involved extensive removal of lower leaves from plants, thus reducing the amount of preferred habitat for the three species of caterpillars in this experiment; and perhaps the strongest factor influencing the low number of parasitoids, (5) this experiment was conducted in the dry season. The high mortality rate of the early instar Lepidoptera collected in the experiment ( $72.34 \%)$ is best explained by non-parasitic factors such as weather and plant factors (Hawkins et al. 1997).

Although no significant difference between intercropping and control treatments was found for abundance of any of the lepidopteran species or parasitism among different treatments, it is possible that the effect of intercropping could not be detected at the small spatial scale of this experiment. Research indicates that parasitoid abundance and diversity, as well as overall parasitism, may be increased near a nectar source (Lewis et al. 1997). Enhanced parasitism closer to food sources is an effect that may be easiest measured in agroecosystems with more scarce nectar sources. The plantation used in this experiment may have low lepidopteran numbers because of the abundance of the $F$. macrophylla nectar source for parasitoids. Therefore, the effect of intercropping may be indiscernible with an experiment of this scale. 


\section{CHAPTER 4: OVERALL CONCLUSIONS AND RECOMMENDATIONS}

Conventional farming in wet tropical forest systems presents a unique set of agricultural and environmental challenges due to high rainfall, low soil nutrient content, extended growing seasons, and high abundance and diversity of pests (Vandermeer 2001). The Lepidoptera and parasitoid study, Lepidoptera diversity survey, and intercropping experiment provide basic ecological information about banana, an important tropical crop, and lay the foundation for more research into biological control.

The parasitoid survey indicated that both tachinids and hymenopteran parasitoids are an important source of mortality for banana pests, and might potentially have controlled three previous outbreak species of Lepidoptera. By focusing on the parasitoid species that are now known to control banana pests, future research on naturally occurring parasitism should focus on investigating those species of parasitoids that have been found to control known Lepidoptera pests. Ideally, this research will (1) involve placing laboratory-reared lepidopteran in the field to better understand parasitism, and (2) look at the entire set of biological factors controlling lepidopteran. These additional biological factors include other natural enemies, such as reptiles, birds, and spiders. These enemies appeared to be abundant in all plantations and have been shown in previous research to play a significant role in controlling lepidopteran pests in banana (Harrison 1963b). This research will help determine if the parasitoids witnessed in this study are currently effectively controlling lepidopteran at rates high enough to be considered effective biological control. 
Hymenopteran parasitoids are known to be negatively affected by organochlorine and organophosphate insecticides (Scott et al. 1990, 1991). This study suggests that tachinids may be more tolerant of insecticides and also benefit indirectly from insecticide effects on other organisms, perhaps due to increased host availability because of lower numbers of parasitic hymenoptera. This apparent negative effect of insecticides on hymenopteran parasitoids but not on tachinids is consistent with results of Matlock (2000). Additional research into the relative toxicity of insecticides to hymenopteran and tachinid parasitoids will help understand why insecticides have apparent opposing effects on these taxa.

Several Lepidoptera recorded in this survey have not previously been reported as banana pests. Two species of Limicodidae, Acharia horida and Acharia apicalis, found throughout plantations, may not have the capability to rapidly increase in population size in banana, or it may be that they have more recently invaded banana. Additional research should include a study of the natural predation and parasitism of these lepidopteran in an effort to better understand their potential significance as a future agricultural pest.

Investigating the distribution and parasitism of lepidopteran species in natural systems would be useful in understanding their role in agricultural systems. Future research should investigate the herbivores present in the Heliconiaceae. It has been hypothizied that pests of Heliconiaceae shifted to the old world native Musaceae (Kress 1991). Therefore, additional research focusing on the lepidopteran and parasitoid community on those Heliconiaceae native to the new world could provide valuable insight into the ecology of those pests on Musaceae. Conducting comparative analysis of 
insect occurrence and natural control on endemic banana relatives in Costa Rica that have similar architecture and habitat, such as Heliconia sp., could provide better understanding of wet tropical lepidopteran communities (Itino et al 1991 and Kress 1991).

The sample size in the intercropping experiment was too small to detect a positive benefit of nectar-producing plants. However, it is quite possible that the widespread distribution of a food source has increased abundance and diversity of parasitoids, therefore decreasing Lepidoptera levels on the plantation. Another reason for not being able to detect different lepidopteran or parasitoid levels between treatments may have been the abundance of fruit rotting in the field and the presence of numerous weed species on the experiment plantation. Floral and extrafloral nectar of weeds, pollen, and rotting fruit sugars provide abundant food for parasitoids (Takasu and Lewis 1995 and Lewis et al. 1997). Therefore, to test for effects of nectar-producing plants, a more sensitive experimental design may be necessary. Future experiments should remove plantation nectar sources that could potentially skew the enhanced parasitism results by mowing, using herbicides, or taking other measures. Alternatively, parasitoid abundance and diversity could be assayed using trapping, as opposed to caterpillar collection and rearing, which is less labor intensive. The benefit of this research, having turned an insufficient number of lepidopteran or parasitoids for a final analysis, is that future research will need to be designed to detect more subtle variations in both lepidopteran and parasitoid levels.

Overall, these three research topics have added much insight into parasitoid function on banana plantations in the Atlantic zone of Costa Rica. This research unveiled 
the parasitoids that have, until this time, been only hypothesized as having controlled populations of Lepidoptera pests. Both agricultural researchers and ecologists can now build on this research to uncover more insight into the complex pest - parasitoid community in Costa Rican wet tropical agroecosystems. 


\section{LITERATURE CITED}

Andersson, M. M. Peters, and R. Shultze-Kraft 2000. Flemingia Macrophylla (Wild.) Merrill. Rome, Italy: Food and Agricultural Organization (FAO).

Broadmann, P.A., C.V. Wilcox, and S. Harrison. 1997. Mobile Porasitoids may Restrict the Spatial Spread of an Insect Outbreak. Joumal of Animal Ecology 66(1): 6572.

CIAT (Centro Internacional de Agricultura Tropical). 2001. Tropical Grasses and Legumes: Optimizing Genetic Diversity for Multipurpose Use (Project IP5). CIAT Annual Report 2001.

CORBANA (Corporacion Bananera Nacional), S.A. 2000. Costa Rica Estadisticas de Exportation de Bananero 1999.

Champion, J. 1963. Le Bananie. Paris: Maisonneuvre and Larose.

Chapman, R.N. 1939. Insect Population Problems in Relation to Insect Outbreak. Ecological Monographs 9(3): 261-269.

Cubillo, D. Personal Communication, 13 September 2001. Guapiles, Costa Rica.

DeVries, P.J. 1987. The Butterflies of Costa Rica and their Natural History, Volume I: Papilionidae, Pieridae, Nymphalidae. Princeton: Princeton University Press.

Dyer, L. Personal Communication, 3 April 2001. San Jose, Costa Rica.

Dyer, L. 2003. Caterpillars and Parasitoids of a Costa Rican Tropical Wet Forest (http://www.tulane.edu/ ldyer/lsacat/index.htm).

Dyer, L.A. and G. Gentry. 1999. Larval defensive mechanisms as predictors of successful biological control. Ecological Applications 9:402-408.

Gaston, K. J., I.D. Gauld, and P. Hanson 1996. Size and Comparison of the Hymenopteran Fauma of Costa Rica. Joumal of Biogeography 23: 15-113.

Gliessman, S.R., E.R. Garcia, and A.M. Amador. 1981. The Ecological Basis for the Application of Traditional Agricultural Technology in the Management of Tropical Agroecosystems. Agroecosystems 7: 173-185.

Godfray, H.J.C. 1994. Parasitoids: Behavioral and Evolutionary Ecology. Princeton: Princeton University Press.

Greathead, D.J., and J.K. Waage. 1983. Opportunities for Biological Control of Agricultural Pesis in Developing Countries. Washington, D.C.: The World Bank. 
Hagen, K.S., R.H. Dadd, and J. Reese. 1984. The Food of Insects, pp.80-111. In Carl B. Huffaker and R. L. Rabb (eds.). Ecological Entomology. New York: John Wiley and Sons.

Hansen, M. 1988. Escape From the Pesticide Treadmill: Alternatives to Pesticides in Developing Countries. Mount Vemon: Institute for Policy Research.

Harrison, J. O. 1964. Factors Affecting the Abundance of Lepidopter in Banana Plantations. Ecology 45(3): 508-519.

Hamison, J.O. 1963. On the Biology of Three Banana Pests in Costa Rica (Lepidoptera: Limacodidae, Nymphalidae). Annals of the Entomological Society of America 56: 87-94.

Harrison, J. O. 1963b. The Natural Enemies of Some Banana Insect Pests in Costa Rica. Joumal of Economic Entomology 56(3): 282-285.

Hawkins, B.A. 1993. Parasitoid Species Richness, Host Mortality, and Biological Control. American Naturalist 141(4): 634-641.

Hawkins, B.A. 1994. Pattern and Process in Host-Parasitoid Interactions. Cambridge: Cambridge Univ. Press.

Hui-Lin, L. 1944. On Flemingia Roxburgh (1812), Non Roxburgh (1803) Versus Morghania J. St.-Hilaire (1813). American Joumal of Botany 31(4): 224-228.

Idrus, A.B., and E. Grafius. 1995. Wildflowers as Nectar Sources for Diadegma insulare (Hymenoptera: Ichneumonidae), a Parasitoid of Diamondback Moth (Lepidoptera: Yponomeutidae). Environmental Entomology 24(6): 1726-1735.

Idrus, A.B., and E. Grafius. 1997. Nector Collecting Behovior of Diadegma insulare (Hymenoptera: Ichneumonidae), a Parasitoid of Diamondback Moth (Lepidoptera: Phtelliale). Environmental Entomology 24(6): 114-120.

Itino, T. 1991. Pollination of the Two Wild Bananas, Musa acuminata subsp. Halwbanesis ond M. salaccensis: Chiropterophily and Ornithophily. Biotropica 23(2): $151-158$.

Janzen, D. H. and W. Hallwachs. 2003. Philosophy, navigation and use of a dynamic database ("ACG Caterpillars SRNP") for an inventory of the macrocaterpilar fauna, and its food plants and parasitoids, of the Area de Conservacion Guanacaste ( $\mathrm{ACG}$ ), northwestem Costa Rica (http:/janzen.sas.upenn.edu).

Jones, D.R. 2000. Introduction to Banana, Abaca, and Enset. In: Diseases of Banana, Abaca, and Enset. Wallingford, England: CAB Intemational. 
Kevan, P. G., and J. G. Baker. 1984. Insects on Flowers, pp. 609-631. In Carl B. Huffaker and R. L. Rabb (eds.), Ecological Entomology. New York: John Wiley and Sons.

Kress, W.J. 1991. New Taxa of Heliconia (Heliconiaceae) from Ecuador. Brittonia 43(4): $253-260$.

Loehr, R. C. 1977. Pollution Control for Agriculture. New York: Academic Press.

Lewis, W.J., J.O. Stapel, A.M. Cortesero, and K. Takasu. 1998. Understanding How Parasitiods Balance Food and Host Needs. Biological Control 11: 175-183.

Lewis, W.J., L.M. Vet, J.H. Tumlinson, J.C. Van Lenteren, and D.R. Papaj. 1990. Variations in Parasitoid Foraging Behavior: Essential Element of a Sound Biological Control Theory. Environmental Entomology 19(5): 1183-1193.

Manley, G.V. 1985. Banana Plants Regulate Larval Feeding Site for Leaf Feeding Moth: Ceramidia butleri (Ctenuchidae, Lepidoptera). Fruits 40(7/8): 467-470.

Matlock, R. B. Jr., and R. Cruz. 2002. An Inventory of Parasitic Hymenoptera in Banana Plantations Under Two Pesticide Regimes. Agriculture, Ecosystems, and Environment 1928: 1-8.

Matlock, R. B. Jr., and R. Cruz. 2003. Ants as Indicators of Pesticides in Banana. Environmental Entomology 32(4): 816-829.

Memmott, J., H.C.J. Godfray, and B. Bolton. 1993. Predation and Parasitism in a Tropical Folivore Community. Ecological Entomology 18: 348-352.

Memmott, J., H.C.J. Godfray, and I.D. Gauld. 2001. The Structure of a Tropical HostParasitoid Community. Journal of Animal Ecology 63(3): 521-540.

Ostmark, E. H. 1974. Economical Insect Pests of Bananas. Annual Review of Entomology 19: 161-175.

Patt, Joseph M., George C. Hamilton, and J.H. Lashomb. 1997. Foraging Success of Parasitoid Wasps on Flowers: Interplay of Insect Morphology, Floral Architecture and Searching Behovior. Entomologia Experimentalis et Applicata 83:21-30.

Patt, J. M., C.H.George, and J.H. Lashomb. 1999. Responses of Two Parasitoid Wasps to Nectar Odors as a Function of Experience. Entomologia Experimentalis et Applicata 90:1-8.

Perfecto, I, and R. Snelling. Biodiversity and the Transformation of a Tropical Agroecosystem: Ants in Coffee Plantations. Ecological Applications 5(4): 10841097.

Price, P. W., C.E. Bouton, P. Gross, B.A., McPheron, J.N. Thompson, and A.E. Weiss. 1980. Influence of Plants on Interactions Between Insect Folivores and Natural Enemies. Annual Review of Ecological Systems 11:41-65. 
Pemberton, R. W., and J. Lee. 1996. The Influence of Extrafloral Nectaries on Parasitism of an Insect Folivore. American Journal of Botany 83(9): 1187-1194.

Powell, W. 1986. Enhoncing Porositoid Activity in Crops, pp. 319-341. In J. Waage, and D. Greathead (eds.). Insect Parasitoids. New York: Academic Press.

Scott, J. G., K. Dong, C. J. Geden, and D.A. Rutz. 1990. Evaluation of the Biochemical Basis of Insecticide Selectivity Between Hose and Parasinoid Species. Environmental Entomology 19(6): 1722-1725.

Scott, J. G., K. Dong, C. J. Geden, D.A. Rutz, and N. Liu. 1991. Comparative Toxicity of Seven Insecticides to Immature Stages of Musca domestica (Diptera: Muscidae) and Two of the Important Biological Control Agents, Muscidifurax roptor and Spalangia cameroni (Hymenoptera: Pteromalidae). Joumal of Economic Entomology 84(3): 776-779.

Sparrow, Helen R., T.D. Sisk, P.R. Ehrlich, D.D. Murphy. 1994. Techniques and Guidelines for Monitoring Neotropical Butterflies. Conservation Biology \&(3): 800-809.

Stephens, C.S. 1984. Ecological Upset and Recuperation of Natural Control of Insect Pests in Some Costa Rican Banana Plantations. Turrialba 34: 101-105.

Takasu, K. and Lewis W.J. 1995. The Role of Learning in Adult Food Location by the Larval Parasitoid, Microplitis croceipes (Hymenoptera: Braconidae). Journal of Insect Behavior 9(2): 265-281.

Thrupp, Lori A. 1990. Entrapment and Escape from Fruittess Insecticide Use: Lessons from the Banana Sector of Costa Rica. International Journal of Environmental Studies 36: 173-189.

University of Texas. 2003. Map of Costa Rica (http://www.lib.utexas.edu/maps/americas/costa_pol87.jpg).

Vandermeer, J. M. 2001. The Agroecosystem: The Modem Vision in Crisis, the Alternative Evolving, pp. 494-518. In R. S. Singh, C. B. Krimbas, D. B. Paul, J. Beatty (eds.). Thinking About Evolution. Cambridge University Press.

Vandermeer, J. M., M. Noordwijk, J. Anderson, C. Ong, and I. Perfecto. 1998. Global Change and Multi-Species Agroecosystems: Concepts and Issues. 67: 122.

Waakers, F.L. 1999. Gustatory Response by the Hymenopteran Parasitoid Cotesia glomerata to a Range of Nectar and Honeydew Sugars. Journal of Chemical Ecology 25(12): 2863-2877.

Wielemaker, Frans. 1981. The Leaf Eating Caterpillar Antichloris viridis Druce (formerly Ceramidia spp.): The Most Abundant Defoliator in Central America (Lepidoptera: Ctenuchidae). Banana Development Corporation of Cost RicaResearch Department, S.A. 
Wesseling, Catherina, L.C. Castillo, C. Elinder. 1993. Pesticide Poisonings in Costa Rica. Scandinavian Joumal of Work and Environmental Health 19: 227-235.

Zar, Jerrold. H. 1999. Biostatistical Analysis $4^{\text {th }}$ ed. New Jersey, Prentice-Hall. 